WALDEN

UNIVERSITY

A higher degree. $A$ higher purpose.

Walden University

ScholarWorks

Walden Dissertations and Doctoral Studies

Walden Dissertations and Doctoral Studies

Collection

$1-1-2010$

\title{
The impact of symptom severity on parent-child interaction and relationships among children with autism
}

Nicole M. Beurkens

Walden University

Follow this and additional works at: https://scholarworks.waldenu.edu/dissertations

Part of the Clinical Psychology Commons, and the Developmental Psychology Commons

This Dissertation is brought to you for free and open access by the Walden Dissertations and Doctoral Studies Collection at ScholarWorks. It has been accepted for inclusion in Walden Dissertations and Doctoral Studies by an authorized administrator of ScholarWorks. For more information, please contact ScholarWorks@waldenu.edu. 


\section{Walden University}

COLLEGE OF SOCIAL AND BEHAVIORAL SCIENCES

This is to certify that the doctoral dissertation by

Nicole Beurkens

has been found to be complete and satisfactory in all respects, and that any and all revisions required by the review committee have been made.

Review Committee

Dr. Magy Martin, Committee Chairperson, Psychology Faculty

Dr. Rodney Ford, Committee Member, Psychology Faculty

Dr. Andrea Miller, Committee Member, Psychology Faculty

Dr. Scott Hershberger, University Reviewer, Psychology Faculty

Chief Academic Officer

David Clinefelter, Ph.D.

Walden University

2010 


\begin{abstract} Children with Autism

by

Nicole M. Beurkens

\author{
M.Ed., Oakland University \\ B.A., Hope College
}

Proposal Submitted in Partial Fulfillment of

The Requirements for the Degree of

Doctor of Philosophy

Psychology
\end{abstract}

The Impact of Symptom Severity on Parent-Child Interaction and Relationships Among

Walden University

August 2010 


\begin{abstract}
Recent estimates indicate that 1 in 100 children in the United States is diagnosed on the autism spectrum. Although research has demonstrated the bidirectional nature of parentchild relations, the effect of child autism symptom severity on parent-child interaction and overall relationships has not yet been explored. This study examined the impact of child symptom severity in children ages 4-15 years, as measured by the Autism Diagnostic Observation Schedule (ADOS), on parent-child interaction, as measured by the Dyadic Coding Scale (DCS), and parent-child relationships, as measured by the Parent Child Relationship Inventory (PCRI). The bidirectional model of socialization informs the study, as it recognizes the mutual impact that parents and children have on one another in the context of parent-child relations. The sample included 25 parent-child dyads, each consisting of a child diagnosed on the autism spectrum and his/her primary parent. Relationships between autism symptom severity, parent-child interaction, and parent-child relationships were explored using multivariate regression analysis. Significant inverse relationships were found between autism symptom severity and parent-child interaction, but no relationship was found between symptom severity and parent-child relationship. Understanding the negative influence of autism symptom severity on parent-child interaction and the lack of impact on overall relationship allows for more effective treatment planning and monitoring of progress over time. Efforts to improve interactions and relationships for these children will lead to significant social change by increasing the effectiveness of treatment programs, enriching family relationships, and improving outcomes across the lifespan.
\end{abstract}



The Impact of Symptom Severity on Parent-Child Interaction and Relationships Among Children with Autism

by

Nicole M. Beurkens

M.Ed., Oakland University

B.A., Hope College

Proposal Submitted in Partial Fulfillment of the

Requirements for the Degree of

Doctor of Philosophy Psychology

\author{
Walden University
}

August 2010 
UMI Number: 3422763

All rights reserved

INFORMATION TO ALL USERS

The quality of this reproduction is dependent upon the quality of the copy submitted.

In the unlikely event that the author did not send a complete manuscript and there are missing pages, these will be noted. Also, if material had to be removed, a note will indicate the deletion.

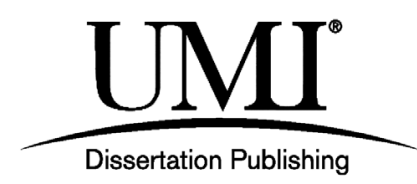

UMI 3422763

Copyright 2010 by ProQuest LLC.

All rights reserved. This edition of the work is protected against unauthorized copying under Title 17, United States Code.

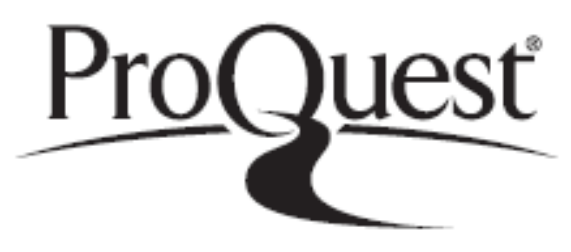

ProQuest LLC

789 East Eisenhower Parkway

P.O. Box 1346

Ann Arbor, MI 48106-1346 


\section{Dedication}

This project is dedicated to my wonderful husband, Bill, and my children Caden, Jonah, Nathan, and Caris. Beginning this doctoral program was truly a family decision, and they have supported me unconditionally throughout the process. May the completion of this dissertation be a model for my children of the value of hard work, perseverance, and ongoing learning. 


\section{Acknowledgements}

I would like to extend my sincere thanks and appreciation to my dissertation committee for their support and guidance throughout this process. Dr. Magy Martin helped me keep the end goal in focus, while carefully guiding me through each required step along the way. Her prompt feedback and unending encouragement was a gift to me over these past 18 months. My appreciation also goes to my committee members Dr. Andrea Miller and Dr. Rodney Ford, who provided me with assistance in the statistics and overall formulation of the study. Many thanks to my editor, John Rottenberg, who has worked his way through numerous drafts and revisions of this research from it's infancy to completion.

My deepest gratitude I give to my husband, Bill Beurkens, who has given me the freedom to pursue this degree and never once doubted my ability to complete it. His ability and willingness to care for our children, our home, and me over the past four years has made this possible. I also acknowledge my four children, who have been so loving and supportive throughout this process (even when they would have liked for Mommy to be doing things more fun than writing)!

I also thank my dear colleagues at the Horizons Center for their unending support and encouragement in my pursuit of this degree. I could not ask for a better group of people with whom to spend my working days! Last, but certainly not least, I would like to extend my appreciation to the wonderful families I have the privilege of serving through my work. These parents and their children with autism are some of the most amazing people I know, and I am truly blessed that they allow me to walk alongside them on their journey. They are the reason I continue the work that I do. Thank you. 
Table of Contents

List of Tables ............................................................................................. ii

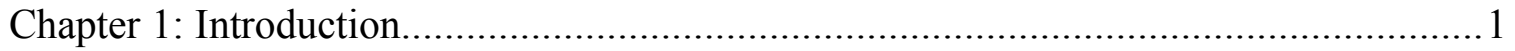

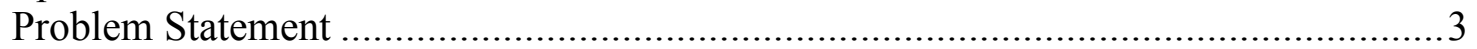

Nature of the Study .......................................................................................... 5

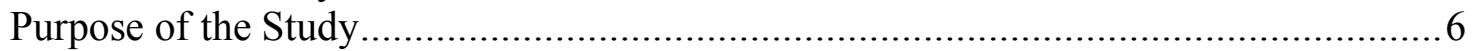

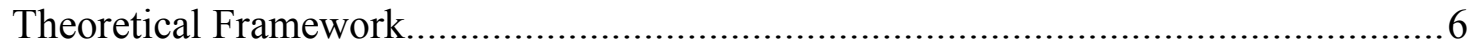

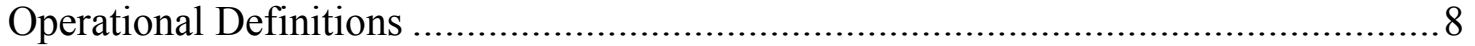

Assumptions, Limitations, and Scope ................................................................ 9

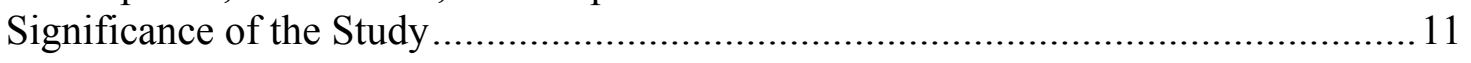

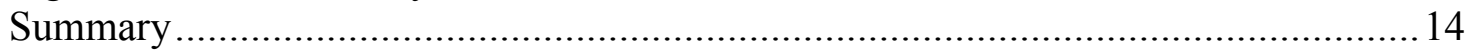

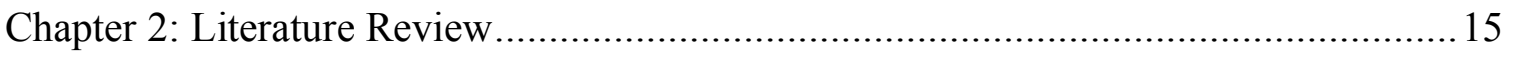

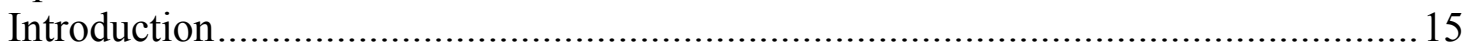

Review of Related Research and Literature................................................... 15

Symptom Severity and Parent-Child Interactions ...................................... 18

Symptom Severity and Parent-Child Relationships ............................................20

Interaction as a Mediator of Symptom Severity and Relationship.......................23

Summary of Literature that Defines the Theory .............................................26

Literature Based Description of Research Variables........................................... 32

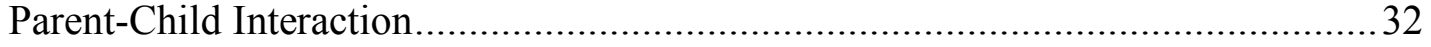

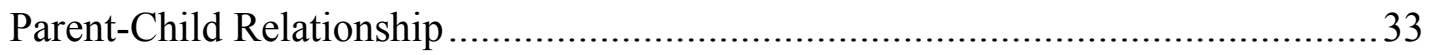

Autism Symptom Severity .......................................................................... 34

Literature Related to the Method and Differing Methodologies................................38

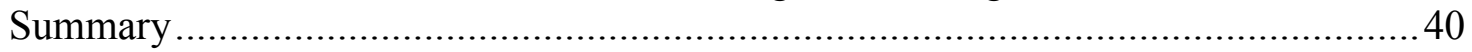

Chapter 3: Research Method................................................................................. 42

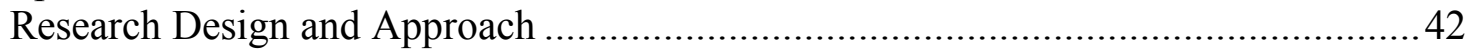

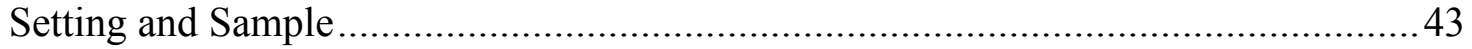

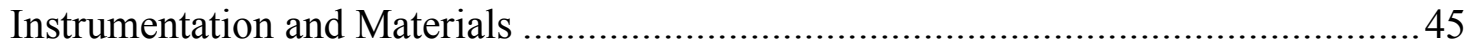

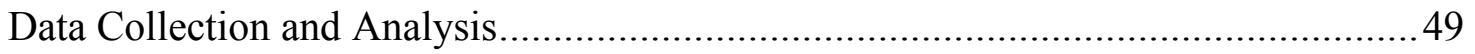

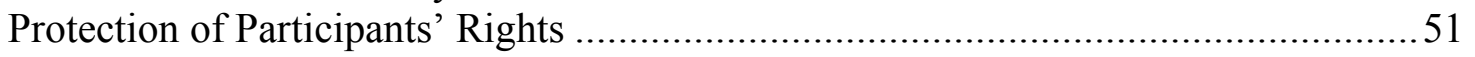

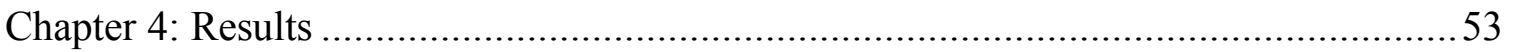

Demographic Characteristics of the Sample........................................................53

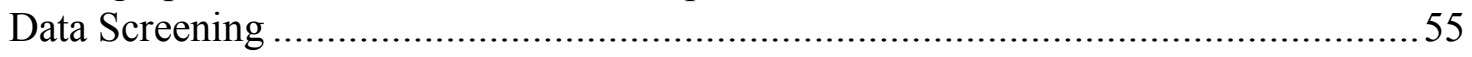

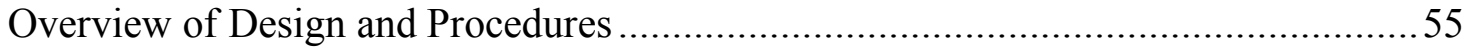

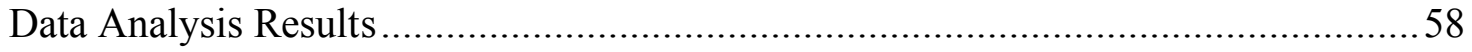

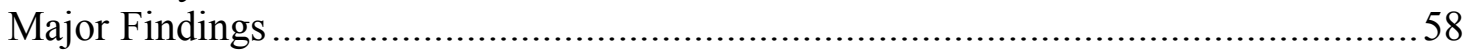




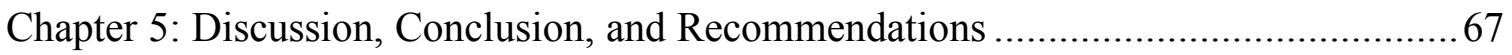

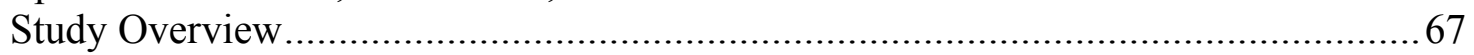

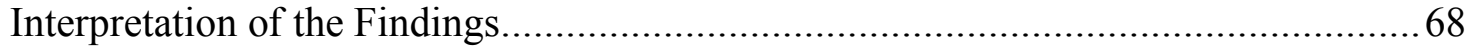

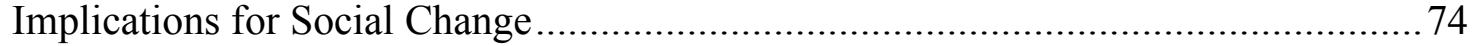

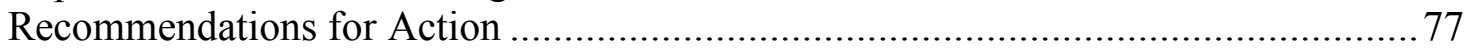

Recommendations for Further Research .......................................................... 78

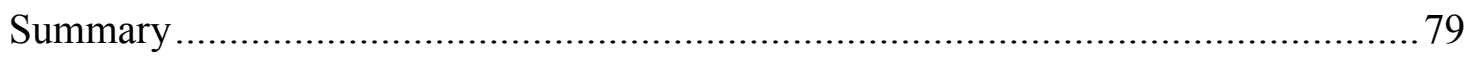

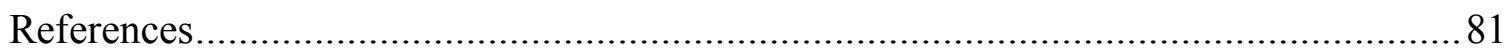

Appendix A: Parent Research Consent Form ....................................................... 98

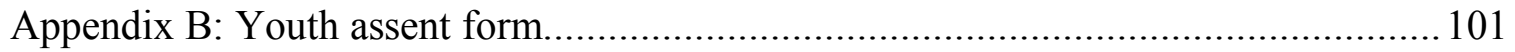

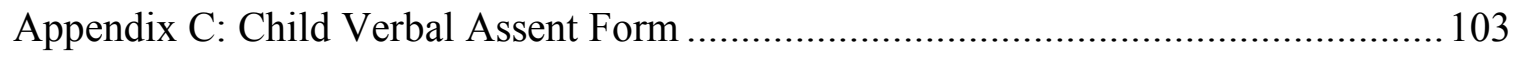

Appendix D: Videotaped Activity Protocol …................................................ 105

Appendix E: Demographic Questionnaire......................................................... 106

Appendix F: ADOS Revised Scoring Algorithms ........................................ 108

Appendix G: Permission to Use Revised ADOS Algorithms ................................... 113

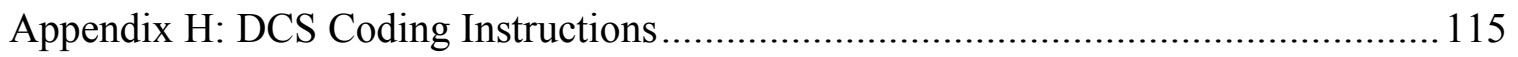

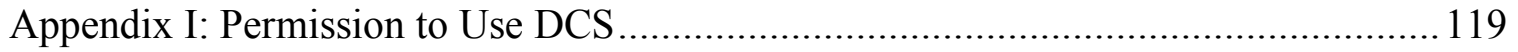

Curriculum Vitae........................................................................................ 120 


\section{List of Tables}

Table 1. Demographic Characteristics of Participants................................................ 54

Table 2. Means and Standard Deviations on Participant Age........................................ 55

Table 3. Means and Standard Deviations for ADOS and the Scales of DSC and

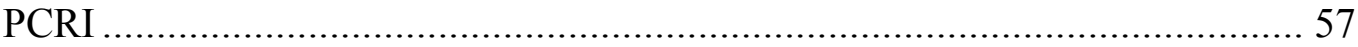

Table 4. Correlation Coefficients for Symptom Severity and Parent-Child

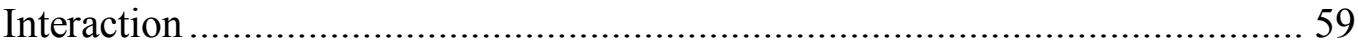

Table 5. Correlation Coefficients for Symptom Severity and Parent-Child

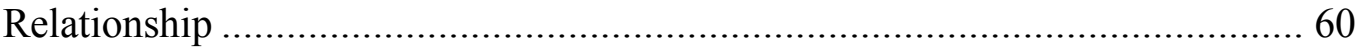

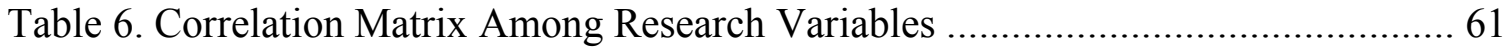

Table 7. Multivariate Regression with ADOS predicting DCS Subscales of Coordination, Communication, Partner Roles, Emotional Expression, Responsivity, Tension/Relaxation, Mood, Enjoyment, and Overall.................. 64

Table 8. Multivariate Regression with ADOS predicting PCRI Subscales of Support, Satisfaction, Involvement, Communication, Limit Setting, Autonomy, and

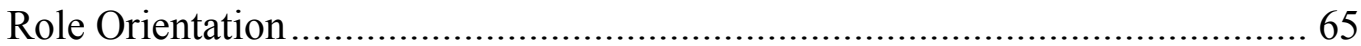




\section{Chapter 1: Introduction}

The bidirectional model of parent-child relations has become prominent in developmental and social psychology, in recognition that both parents and children impact each other's development as well as the status of the relationship overall (DeMol \& Buysse, 2008). Researchers on autism have begun to explore the ways in which parent and child factors influence relationships and development, but research concerning the influence of child symptom severity on parent-child interaction and relationships has not yet been conducted (Siller \& Sigman, 2008). The proposed study begins to address this gap in the literature by examining the relationship of child autism symptom severity to aspects of parent-child interaction and relationships. A detailed understanding of this relationship has the potential to increase understanding of the role of parents in targeting symptom reduction and improving developmental outcomes for children with autism.

Bidirectionality has been identified as an important characteristic of parent-child interactions and relationships, meaning that both parents and children exert influence over each other (Kuczynski, Loulis, \& Koguchi, 2003). Parent traits and behaviors impact the child and child traits and behaviors impact the parents - thus the bidirectional dynamic. Interactions between parent and child can be viewed in the context of the overall relationship, thus allowing for both microanalysis and macroanalysis of parent-child relations. The concept of bidirectionality is therefore important when considering the impact of a child's autism symptoms on parent-child relations.

To date, there has been contradictory evidence in the literature concerning bidirectional components of parent-child relations in autism. Research has shown that some aspects of overall relationship, such as attachment, are not impacted by autism (Yirmiya \& Sigman, 2001), while 
other areas, such as shared attention, are impacted (Hobson, 2004). This ambivalent evidence has created a need for research specifically targeting both parent-child interactions and parentchild relationships. Interactions are defined as the moment-to-moment experiences between parent and child that compound over time to comprise the broader parent-child relationship (Kuczynski, Loulis, \& Koguchi, 2003). The relationship between parent and child is the comprehensive history of interactions over time that provides a context for future interactions over the course of the lifespan (Harach \& Kuczynski, 2005). Examining both parent-child interaction and parent-child relationships allows for understanding the immediate and long-term nature of parent-child relations. Research conducted in the field of autism has indicated that the disorder creates disruptions in parent-child interactions, while leaving aspects of the overall parent-child relationship unaffected (Hobson et al., 2008). Additional information is needed to understand the mechanisms by which autism impacts elements of interaction and relationship.

The bidirectional model of parent-child relationships has led to a significant body of research into the processes by which child development occurs through relationships with other people (Hobson, 2004; Trevarthen \& Aitken, 2001). In order for children to become socialized into their cultures - including the development of communication, social, and thinking skills relevant to that culture - they must have continuous opportunities to engage in reciprocal interactions and relationships with trusted adults. Tomasello and colleagues (2005) assert that it may be a uniquely human ability to engage in shared goals, intentions, and attention. The relationships developed with parents from birth forward begin to shape children's understanding of themselves, others, and the world around them (Trevarthen \& Aitken).

One of the aspects that may impact these processes is the severity of autism symptoms. Given the spectrum nature of autism, it seems logical to consider the severity of core symptoms in relation to breakdowns in parent-child interaction and relationships (Markus, Mundy, Morales, 
Delgado, \& Yale, 2000). Research in the realm of parent-child attachment in nonautistic populations has shown that with increased attachment deficits come increased levels of disruption in parent-child interaction (Humber \& Moss, 2005). The premise of this study extends this research to children with autism, hypothesizing that the more severe the child's autism symptoms the more disrupted the parent-child interaction, which leads to a more disrupted and negative relationship overall. These interactive and relational disruptions lead to a failure to engage in the kinds of interpersonal activities that lead to cognitive, communicative, and social competence from an early age. Additional research regarding autism symptomology, child development through relationships, and bidirectional parent-child relations is detailed in Chapter 2.

\section{Problem Statement}

Researchers investigating the core deficits of autism have identified a set of salient cognitive, communicative, and social abilities that pervasively impact the ability to engage in meaningful communication and social relationships (Sigman et al., 2006). However, most current treatment approaches do not target these specific areas (Charman et al., 2004), nor do they follow the research recommendations regarding incorporation of parents into the treatment process (Howlin, 2000). The outcomes of these treatments in terms of core deficit symptom reduction, therefore, has been limited (Bodfish, 2004), with long-term outcome studies showing that most individuals with autism who receive available treatments do not develop independence (Eaves \& Ho, 2008).

The abilities that constitute deficiencies in autism are known to develop in typical children through interactions and relationships with parents from infancy throughout the childhood years (Hobson, 2004). The bidirectional model of socialization describes the reciprocal impact that children and parents have on one another through their interactions and 
relationships, and the ways in which child development is influenced as a result. While it is recognized that parents and children influence each other in a bidirectional process, little has been done to investigate how this occurs in the interactions and relationships between parents and children with autism (Siller \& Sigman, 2002). The impact of autism symptoms on the ability to engage in relationships that allow this development has been well documented. What has not received equal attention are the mechanisms by which a child's autism symptoms impact interactions and relationships with parents, therefore impacting the developmental process. It is essential to establish this in order to identify ways in which relationships may be utilized to impact symptoms positively.

In order to better understand how parents can play a role in child symptom reduction, attempts are being made to research the ways in which parent-child relationships are disrupted by autism as well as protective factors that lead to more productive relationships. Identifying both the positive and negative factors that occur in the context of parent-child relations in autism will lead to a better understanding of how the bidirectional parent-child relationship can relieve symptoms and promote more typical development in the child. This study will add to the psychological research that exists on bidirectionality in parent-child relationships in autism by investigating the influence of autism symptom severity on aspects of parent-child interaction and overall parent-child relationships. It was expected that increases in symptom severity will negatively impact moment-to-moment interactions and some aspects of the parent-child relationship. A fuller understanding of these relationships will support the development of interventions directed at the core deficits of autism, so as to improve outcomes for this population. 


\section{Nature of the Study}

The following research question and hypotheses have been developed based on a review of existing literature in the areas of autism, parent-child interaction, and parent-child relationships. A number of measures will be used in this study, along with the collection of demographic information. The Autism Diagnostic Observation Schedule (ADOS) measures core autism symptom severity and will be conducted to confirm child diagnosis. Aspects of parentchild interaction will be measured using the Dyadic Coding Scale (DCS). Parent-child relationships will be evaluated via the Parent Child Relationship Inventory (PCRI). A more detailed description of the nature of this quantitative study can be found in Chapter 3 .

\section{Research Question 1}

RQ1: Does autism symptom severity, as measured by the Autism Diagnostic Observation Schedule (ADOS), predict parent-child relationship, as measured by the Parent Child Relationship Inventory (PCRI) and parent-child interaction, as measured by the Dyadic Coding Scale (DCS)?

$\mathrm{H} 1_{\mathrm{o}}$ : Autism symptom severity, as measured by the Autism Diagnostic Observation Schedule (ADOS), does not predict parent-child relationship, as measured by the Parent Child Relationship Inventory (PCRI) and parent-child interaction, as measured by the Dyadic Coding Scale (DCS).

$\mathrm{H} 1_{\mathrm{a}}$ : Autism symptom severity, as measured by the Autism Diagnostic Observation Schedule (ADOS), predicts parent-child relationship, as measured by the Parent Child Relationship Inventory (PCRI) and parent-child interaction, as measured by the Dyadic Coding Scale (DCS). 


\section{Purpose of the Study}

The purpose of this study is to examine quantitatively the effect of severity of autism symptoms in children ages 4-15 years on parent-child interactions and relationships. Specifically, I identified how severity of social-communication symptoms are related to the parent-child relationship. The parent-child relationship is comprised of many elements, including, but not limited to, family supports, parenting satisfaction, level of autonomy, the parent's involvement with the child, parenting style, quality of communication, and the role parents take with the child. Parent-child interaction was also analyzed in relation to severity of social-communication symptoms. Research-identified elements of parent-child interaction include constructs such as coordination, communication, roles, emotional expression, responsivity, level of tension, mood, and enjoyment. Results of this investigation add to the growing body of literature on relational elements requiring consideration in autism symptom reduction efforts.

\section{Theoretical Framework}

The bidirectional model of child socialization, first described by Bell (1968), best explains the influences parents and children have on each other within their interactions and relationships, and how the child's development is impacted as a result. Unlike prior unidirectional models of parent-child relationships that recognized only the impact of parents on their children, this model emphasizes the mutual influences parents and children have on each other (Kuczynski, 2002). Parent-child relationships are viewed as the result of interactions that evolve over time, and as providing the overall context in which parent-child interactions occur (Kuczynski et al., 2003). Interactions between parent and child can be viewed in the context of the overall relationship, thus allowing for both microanalysis and macroanalysis of parent-child relations (Loulis \& Kuczynski, 1997). 
Though parents were once viewed as being in a position of absolute control and power over children, it is now recognized that there are many ways in which children exert influence over parent cognition and behavior (Kuczynski, 2003). Child characteristics, such as severity of symptoms and behaviors, influence parents via parent-child interactions and relationships.

Parents and children constantly affect each other in an ongoing transactional process. There is a parent-child partnership created whereby both influence the development of the other and the relationship as a whole (De Mol \& Buysse, 2008).

Research on bidirectional influences in parent-child relations has identified ways in which child impairments and disabilities impact parents, and thus the quality of interaction and relationships between them. Sensory motor impairments, hyperactivity, and irritable temperament were some of the initial conditions found to impact child interactions and relationships with parents (Bell, 1968; Sameroff \& Chandler, 1975). A significant amount of research has demonstrated that children impact their own development through their relationships with parents (Cummings, Davies, \& Campbell, 2000). This occurs because child symptoms lead to parenting stress, which alters parenting behavior, and perpetuates the child's difficulties (Hastings, 2002).

A more thorough analysis of how child characteristics and symptoms impact development through relationships has occurred in research on human intersubjectivity. This area of bidirectional research has provided a better understanding of how children develop cognition, language, and self-regulation through their relationships with others. When a child has symptoms that negatively impact the ability to engage in fluid interactions with parents, the result is less emotional attunement between parent and child, less motivation to engage in and respond to interactive experiences, and poorer quality parent-child interactions and relationships overall. This leads to reduced awareness of self and others, limited communication, poor self- 
regulation, and deficient cognition (Trevarthen \& Aitken, 2001). Impoverished intersubjectivity is recognized to be a critical element in the manifestation of autism symptoms and the driving force behind disrupted parent-child interactions and relationships in this population (Hobson, 2004; Ruble et al., 2008).

Research on the bidirectional model provides information critical for understanding how the symptoms of autism may disrupt interactions and relationships with parents and, thereby, many aspects of child development overall. A discussion of the influence of symptom severity on parent-child relations requires consideration of bidirectional factors that influence the relational dynamics that shape ongoing child development. Chapter 2 includes a more detailed description of this model, as well as specific research related to the influence of autism symptoms on parent-child interaction, parent-child relationships, and potential mediating factors.

\section{Operational Definitions}

Attachment: The emotional bond that forms between parent and child, and provides an ongoing connectedness between them (Bowlby, 1988).

Autism: The generic term used to describe individuals diagnosed with Autistic Disorder, Asperger's Disorder, or Pervasive Developmental Disorder-Not Otherwise Specified; often used interchangeably with the term "ASD” (Caronna et al., 2008).

Autism Spectrum Disorder (ASD): The generic term used to describe individuals diagnosed with Autistic Disorder, Asperger's Disorder, or Pervasive Developmental DisorderNot Otherwise Specified; often used interchangeable with the term "autism" (Caronna et al., 2008).

Bidirectionality: Describes the influence of parents on children, and children on parents in the context of interactions and relationships (Kuczynski, Loulis, \& Koguchi, 2003). 
Core Deficits: The root problems in areas such as communication, socialization, and cognition that create the constellation of impairments and symptoms seen in autism (Sigman et al., 2006).

Intersubjectivity: The awareness of you-and-me as separate entities with the ability to be socially and emotionally attuned with one another. This develops from birth forward in typical development and leads to cognitive, communication, and social abilities (Trevarthen \& Aitken, 2001).

Parent-Child Interaction: The specific moment-to-moment experiences that occur between parent and child that make up the greater parent-child relationship. Parent-child interaction is bidirectional in nature, with parents and children exhibiting influence over each other (Kuczynski, Lollis, \& Koguchi, 2003).

Parent-Child Relations: A general term encompassing both interactions and relationships between parent and child (Kuczynski, 2003).

Parent-Child Relationship: The history of parent-child interactions over time that create a context for future interactions and allow for development across the lifespan (Harach \& Kuczynski, 2005).

\section{Assumptions, Limitations, and Scope}

\section{Assumptions}

An assumption is made that study participation is voluntary, and that child and parent participants are not coerced to participate. It is also assumed that parent participants have the ability to comprehend survey questions, and will provide truthful responses to demographic and other questions. The tools utilized are all assumed to measure what they purport to measure. Finally, an assumption is made that past or current treatment does not impact results, as only 
current symptom severity and aspects of parent-child interaction and relationships are being analyzed.

\section{Limitations}

There are a number of limitations that apply to the proposed study. Given that a convenience sample is being utilized, the sample population may not be representative of the larger population of parents and children with autism. Responses may be biased based on the willingness of various families to participate. Small sample size is another limitation. While the number of participants proposed is adequate for conducting data analysis, there is limited ability to generalize findings to the population at large.

Data gathered on the parent-child relationship will be based on a self-reported survey. Therefore, parent reports will be based on their own knowledge and subjective perceptions of their relationships with their children. Demographic data will also be based on participants' selfreports. Survey use has inherent limitations that are not unique to this study. Participants may provide responses that portray themselves, their child, and/or their relationships in a more positive light. Despite these limitations, such surveys are frequently used in research to provide valuable information (Babbie, 1998).

The proposed study is also limited by design. Multivariate regression analysis will be used to establish the presence and strength of relationships between variables. However, causal relationships between the variables cannot be established using these analyses. Despite these limitations, study designs utilizing multivariate regression analysis are commonly used and considered statistically sound (Babbie, 1998).

\section{Scope}

The scope of this project is limited to the proposed population, which includes only children with autism ages 4-15 and their parents in the West Michigan area of the United States. 
Therefore, results will not indicate whether the relationships found are specific to autism or whether they may also be indicative of other child populations.

\section{Significance of the Study}

A valuable aspect of this study is that it addresses a significant gap in the literature, namely how autism symptom severity influences parent-child interaction and relationships. There is a need to understand more about the various dynamics that influence parent-child interaction and relationships, and how these impact the overall development of children with autism. This study is also original, in that there is no previous research investigating the connection between the variables of child symptom severity and aspects of parent-child interaction or relationships. Very few studies have examined how severity of symptoms impact parent, family, or child variables beyond the increased stress parents experience as a result of their child's symptoms. The proposed study addresses core issues related to these underdeveloped areas in the research literature.

An additional strength of this study is the verification of child diagnosis prior to determining participation. Rather than accepting parent report or documentation as evidence of the presence of an autism spectrum disorder, symptoms and diagnosis will be confirmed with the Autism Diagnostic Observation Schedule (ADOS). This will allow for a clearer understanding of participant symptoms and severity levels based on scores obtained through structured observations. It also helps ensure that participating children fit the criteria for inclusion in the study.

As the number of children diagnosed with ASD continues to rise, it becomes increasingly crticial to identify factors that impact development in the defining symptom areas. Statistics released by the National Survey of Children's Health provide evidence that the number of American children being diagnosed with autism may now be one per every 100 children (Child 
and Adolescent Health Measurement Initiative, 2007). This massive increase in the number of children with pervasive developmental needs places an increased resource burden on society as a whole, and on individual families in particular. It is estimated that the cost to provide services over the lifetime of an individual with autism is approximately 3.2 million dollars, with annual spending in the United States for care of all individuals with autism exceeding 35 billion dollars (Ganz, 2007). While research shows that adults with autism work at a higher rate than adults with other disabilities, they generally work many fewer hours and earnfar less. Due to these factors, adults with autism are the most costly to serve throughout their lifespan (Cimera \& Cowan, 2009).

Educators are stuggling to educate students with autism in ways that meet their needs while maintaining fiscal responsibility (Winerman, 2004). There is great debate throughout the country over whether health insurance companies should pay for some or all of the treatment these children require, with companies arguing that autism is an educational problem and not a medical condition (Freudenheim, 2004). Questions abound regarding how care will be provided for individuals with autism as they age, particularly those who are unable to develop skills required for success in the workplace and independent living.

While society as a whole bears an increased economic burden for autism, individual families also sustain tremedous economic and other stressors. These families deal daily with the physical, emotional, mental, and financial stressors that accompany caring for a child with autism. Many families incur additional expenses for therapies and material needs, must reduce their workloads and pay, and cope with increased stress levels (Woodgate, Ateah, \& Secco, 2008). Research has also shown that family life suffers when a child has autism, including strained relationships, increased divorce rates, sibling issues, and loss of relationships within the larger extended family (Higgins, Bailey, \& Pearce, 2005). Previous research has highlighted the 
less tangible effects of autism on parents in particular, such as a sense of loss of oneself and less social contact (Cashin, 2004)

Autism clearly has a significant impact on the quality of life of individuals with the diagnosis as well. Research has shown that the majority of these individuals, even those with average or higher intellectual functioning, do not lead independent lives as adults. The core deficits of autism create obstacles to obtaining and maintaining meaningful employment, independent housing, and reciprocal relaitonships within families and communities (Bernard et al., 2001; Eaves \& Ho, 2008). Thus, despite the progress made thus far in understanding and treating the disorder, many individuals with autism are failing to attain a satisfying quality of life.

The vast needs that autism presents on societal, familial, and individual levels make it imperative that researchers address ways in which to support the development and functioning of individuals with autism. While there is much research directed at exploring the causes of autism, less attention is focused on how to help the many individuals currently afflicted with the disorder. This study will help identify the connections between symptom severity and parentchild interaction and relationships. At the macro level, understanding how symptom severity in the child impacts parent-child interaction and relationships may inform approaches seeking to involve parents in symptom improvement. On a micro level, identifying parenting behaviors that promote more positive parent-child relationships may lead to more positive family relationships and greater overall family stability. On an individual level, understanding how to best support relational development between parent and child will allow for more satisfying relationships, and potentially greater levels of independence and fulfillment for individuals with autism. 


\section{Summary}

The massive increase in the number of children diagnosed with autism has created a need for increased research into how development is disrupted in autism and, consequently, how best to support the obstacles facing these individuals. This chapter presented an overview of literature pertaining to autism symptoms, parent-child interaction, and parent-child relationships. The purpose of the proposed study is to identify ways in which autism symptom severity influences parent-child interaction and relationships, and potential mediating factors. This has significance for improving understanding of autism and how parent-child relations may influence symptoms. It will add to the growing amount of autism research literature focused on bidirectional socialization models and parent-child dynamics.

Chapter 2 of this proposal provides an extensive review of pertinent literature related to autism symptoms, parent-child interaction, and parent-child relationships. Included within this chapter is an overview of the bidirectional model of socialization and development. Chapter 3 describes the proposed research methodology and rationale for a quantitative study. Justification for participant criteria, sample selection, data collection methods, and data analysis is also provided. Chapter 4 will provide a description of the data and the results of the study. Chapter 5 will present the conclusions developed based on the results, in addition to limitations, implications for the field, and potential future research directions. 


\section{Chapter 2: Literature Review}

\section{Introduction}

This literature review on parent-child relations in autism will demonstrate the need for ongoing research regarding the effects of symptom severity on various aspects of parent-child interaction and relationships in children with autism. I searched for and obtained literature from multiple research databases using both the EBSCO Host research database at Walden University, and the database at Spectrum Health Medical Library. Specific databases searched included PsycINFO, PsycARTICLES, Academic Search Premier, Medline, PubMed, Google Scholar, and ERIC. The following search terms were used in isolation and various combinations: autism, disabilities, parent-child interaction, parent-child relationships, bidirectionality, transactional model, child socialization, child development, parent characteristics, and child characteristics. The majority of the work cited has been published within the past 10 years, with the exception of seminal work in the field.

The first section is a review of research related to the proposed study, including research on symptom severity, parent-child interaction, and parent-child relationships in autism. The research gap concerning the specific impact of autism symptom severity on parent-child interaction and relationships is noted. The second section identifies the literature that informs the bidirectional model being used in this study. A discussion of the literature basis for the proposed variables is contained in the third section. Finally, the fourth section includes a discussion of literature on the proposed research methods.

\section{Review of Related Research and Literature}

A rich history of research on typical child socialization and development has yielded critical insights regarding the relational nature of development in the areas of communication, 
socialization, and cognition that are implicated in the core deficits of autism. While a unidirectional emphasis of parent effects on children once dominated theories of child socialization, the field has shifted to a bidirectional model that recognizes the family as the major arena for socialization and parents as the primary vehicles for child cognitive and emotional growth (Kuczynski, 2003). Some researchers in the field of autism have begun to study aspects of symptom development and improvement using a bidirectional model (Sigman \& Ruskin, 1999). However, the need for increased research targeting parent-child interactions and relationships in autism has been raised (Aldred, Green, \& Adams, 2004).

The incidence of autism has been rising steadily over the past 10 years in the United States and around the world (CDC, 2007). Research conducted worldwide in the 1980s found that .4-.5 out of 1,000 children were diagnosed with autism. Ten years later, research on autism incidence indicated that 2-6 in 1,000 children were diagnosed with autism. The most recent estimates released by the National Survey of Children's Health (Child and Adolescent Health Measurement Initiative, 2007) state that 1 in 100 children in the United States is diagnosed with an autism spectrum disorder. The reasons for this exponential increase are not yet fully understood, though a combination of genetic and environmental factors are thought to be at work in the development of this disorder (Müller, 2007). As the number of children affected by autism continues to rise, so does the need to understand and treat the disorder in ways that meaningfully impact the lives of those affected and their families.

Exploring the role of parents as it relates to autism has been avoided by some due to concerns about alienating parents and returning to attitudes from the early history of the field of autism that blamed parents (specifically mothers) for the child's autism (Siller \& Sigman, 2002). There continues to be an undercurrent of parents feeling blamed by professionals for their child's autism (Beals, 2003). Understanding how the deviant pathway of development in autism occurs, 
however, necessitates an investigation of how influences outside the child promote the expression of this disorder. This analysis involves parents who have the primary role of socializing their children. It is possible, however, to investigate the parent-child relationship and specific elements of the interaction that lead to deviant development without blaming parents for the autism itself. This is where understanding parent-child interaction as a bidirectional process becomes essential. Within this bidirectional model there is an inherent recognition that the autism itself, which is outside the parents' control, influences the parents' interactions with the child. It is very likely that there are specific parent behaviors that encourage and impede development in this population, just as happens in typically developing and developmentally delayed populations (Siller \& Sigman, 2002).

The bidirectional theory of parent-child interaction and relationships asserts that not only do characteristics and behaviors of parents influence children, but characteristics and behaviors of the child impact parents as well. A concrete area in which to search for insight regarding the influence of a child's autism on parent-child relations is that of symptom severity. There is wide variance among individuals diagnosed with autism, both in core deficits and co-occurring conditions and symptoms. Mental impairment is a commonly co-occurring diagnosis among individuals diagnosed with autism, and the severity of this impairment can greatly impact overall presentation and response to intervention (Howlin, 2000). It has been suggested that symptom severity in autism is determined by the interplay between constitutional vulnerability and environmental factors (Müller, 2007). Scarr and McCartney (1983) posited that the child's early characteristics have an indirect impact on their future outcome, as mediated by the child's social environment. Child characteristics early on cause parents to respond to them in certain ways, which then shape the experiences they have and, therefore, their development as a result of those experiences. This occurs even in typical development, where early child characteristics 
surrounding joint attention and language affect subsequent development in the quality of parentchild interaction (Markus et al., 2000). It is clear that severity of child characteristics can have an increased detrimental effect on the moment-to-moment interactions and overall relationships between children and their parents.

\section{Symptom Severity and Parent-Child Interactions}

Research within and outside of the autism literature supports the connection between severity of child symptoms and aspects of parent-child interaction. School-age child attachment research has indicated that more severe attachment symptoms lead to greater disruption in aspects of parent-child interaction (Humber \& Moss, 2005). There is also evidence to suggest that parents of children with atypical response patterns may alter their style in an attempt to engage their child more successfully. Studies show that mothers of preterm infants, for example, tend to overstimulate and overwhelm their infants with language and interaction as a result of the children's atypical expressive responses (Reissland \& Stephenson, 1998; Salerni, Suttora, \& D'Odorico, 2007). These infants tend to be more passive communication partners, showing less response and less initiation overall. The mother's response is to be more active and overbearing in an attempt to gain some kind of response from the child. Rather than forming an emotionally attuned dyad, the mother becomes a much more active partner in order to compensate for the infant's lack of responsiveness and initiation. This process of parents shifting their response patterns and engagement due to the child's atypical behaviors has been likened to a vortex that pulls the parent progressively deeper into the realm of the child's impairments, thus significantly disrupting the social parent-child relationship (Cashin, 2004).

Mastery motivation, or willingness to persevere in the face of challenges, is also significantly connected to maternal responses to child symptoms in children born preterm. A study of mother-child dyads indicated that maternal response to child distress was the most 
significant factor in promoting mastery motivation, above and beyond any cognitive factors on the part of the child (Young \& Hauser-Cram, 2006). This provides additional evidence of the influence child symptoms have on interactions with parents and how this influence can negatively impact the child's development of mastery motivation, among other things.

Research has demonstrated the influence of child attention and emotionality symptoms on parent behavior. Children with high levels of negative emotionality and poor attention/focus in the first two years of life have lower IQ scores over time than other children. This provides evidence of the long-term developmental implications of specific child characteristics. One hypothesis for these outcomes is that this combination of symptoms, including poor attention and irritability, reduce awareness and information processing on the part of the child and, concurrently, reduce the desire of parents and others to interact with the child in order to provide opportunities for cognitive stimulation and growth (Lawson \& Ruff, 2004). Symptoms of inattention and emotional negativity impact social development, with greater inattentive and negative behaviors associated with less social competence (Belsky, Friedman, \& Hsieh, 2001). Due to the social aspects inherent in IQ tests, it is possible that attention and emotionality lead to reduced social competence and, therefore, lower IQ scores over time (Lawson \& Ruff, 2004).

The disruption in parent-child interaction created by a child's autism symptoms is highlighted in a case study of a child and her parents followed from infancy through early childhood (Hedenbro \& Tjus, 2007). From the nine-month observation forward, it was evident that the parents were more stressed in the presence of their daughter than they had been previously or as compared to other parents. They made more attempts to get a response from their daughter, and made more positive vocalizations to praise any efforts the child made to engage with them. In the area of object focus, already at age 9-months, the child was showing a preference for orienting toward objects as opposed to her parents. As observations continued 
over time, the parents began to initiate more and more objects into their interactions as compared to parents of other children. The interactions became more controlled by the child's temperament and preference than by the parents' instinctual sense of guiding her. This is a pertinent example of how children influence parent behavior within interactions to their developmental detriment.

Researchers have shown that caregiver responses vary in relation to the child's severity of autism symptoms. The more verbal and cognitively capable the child, the more caregivers engage in mutual play and positive feedback. Parents of children with autism who have poorer joint attention and fewer expressive language skills spend more time keeping their child physically contained and oriented to promote attention to task, as compared to parents of typically developing and cognitively impaired children (Kasari, Sigman, Mundy, \& Yirmiya, 1988).

A study of the connections between parent responsiveness and child initiation in autism (Ruble et al., 2008) showed that the ability of children to initiate social interactions with adults was significantly associated with the degree of parent responsiveness. Child and parent demographics were not associated with parent interactions in this study, including the child's adaptive behavior scores or cognitive level. These findings are inconsistent with earlier findings by Spiker, Boyce, and Boyce (2002) that child demographics can influence parent interactions between parents and their children.

\section{Symptom Severity and Parent-Child Relationships}

Researchers have identified a number of ways in which child symptom severity impacts parents and the quality of the parent-child relationship overall. Stress and other factors that accompany parenting a child with atypical developmental characteristics can create unresolved negative feelings toward the child, alter parent expectations, and lead to a reduced sense of 
parenting competence. These disturbances negatively impact the parent-child relationship, as well as ongoing child behavior and development (VanHooste \& Maes, 2003).

Use of a bidirectional socialization lens for viewing the parent-child relationship indicates that, the more severe a child's autism symptoms, the more disrupted parent-child interactions would be, the more stress the parent would experience, and the less satisfaction the parent would have with parenting. While the system of parent-child interaction appears to be disrupted by autism regardless of symptom severity, increases in severity may throw off the system's balance in greater ways, thus creating much more powerful disruptions in the ways parents and children relate over time. Mothers of children with autism, for example, have higher stress levels and more psychological distress than mothers of children with other developmental disabilities or who are developing typically. In addition, the higher the level of child problem behaviors, the higher the levels of parent stress and psychological distress (Estes et al., 2009). A recent study showed that greater severity of autism symptoms was associated with higher levels of individual and family burden (Stuart \& McGrew, 2009). This fits with other research on a variety of disabilities showing that symptom severity is associated with greater levels of burden for parents and the family system as a whole, thus creating more strained relationships overall (Baker, Blacher, \& Olsson, 2005; Pakenham, Samios, \& Sofronoff, 2005; Warfield, 2005).

A recent study by Hoffman and colleagues (2009) showed a significant relationship between child autism symptom severity and mother-child relationships. They found that the only relational element not impacted by symptom severity was degree of closeness, or attachment level, between mother and child. All other areas, such as parent health, level of depression, and perceptions of spouse, were increasingly negative as the severity of child impairment increased. It appears that, as the child-directed inappropriate developmental pathway is perpetuated, the 
parent's stress and frustration level rises and level of satisfaction with interaction and the parenting process in general declines.

The subject of attachment in autism, specifically as it connects to parent-child relationships, requires special consideration due to seeming contradictory evidence in the literature. While it is seems obvious that the presence of autism impacts participation in the relationships that allow for typical development to occur, the connection is far from simple. Attachment research in autism sheds some important light on this topic.

Attachment is described by Bowlby (1982) as the "affectional bond or tie that an infant forms between himself and his mother figure." This bond is important for the development of later cognition, communication, and socialization. One of the premises of attachment theory is that the degree to which children feel secure in their relationships with attachment figures is directly correlated with the degree of consistent warm care received from those figures (AlYagon \& Mikulincer, 2004). Insecure attachment is thought to lead to a variety of psychological problems, including personality disorders, anxiety, and depression (Davila \& Levy, 2006).

Attachment research in autism has shown that children with autism exhibit attachment patterns similar to what is seen in other groups of children (Willemsen-Swinkels et al., 2000; Yirmiya \& Sigman, 2001). As in groups of typically developing children, approximately $50 \%$ of children with autism develop secure attachment with their caregivers. The percentages of children with autism who develop other, less secure forms of attachment also are aligned with what would be expected in other groups of children. Given the impairments in socialization, communication, and cognition exhibited by children with autism, it seems surprising that they would develop secure attachments similar to children without autism.

These studies (Willemsen-Swinkels et al., 2000; Yirmiya \& Sigman, 2001) show that children with autism clearly distinguish between caregivers and strangers. Furthermore, though 
secure attachment is connected to a variety of developmental competencies and greater parental sensitivity, it is not related to the severity of autism symptoms (Koren-Karie et al., 2009). While autism impacts a child's ability to establish reciprocal relationships with others, it may not impact the development of appropriate attachment relationships, regardless of symptom severity. It seems, therefore, that some aspects of bidirectional parent-child relations may be impacted by symptom severity, while other areas may remain unaffected. Understanding which elements of parent-child interaction and relationships are affected and which are unaffected by symptom severity will aid in understanding how child development overall is impacted.

\section{Interaction as a Mediator of Symptom Severity and Relationship}

While the impact of child characteristics and symptoms on parent-child relations is recognized, research also shows it necessary to consider factors that may mediate the impact of these symptoms on the overall parent-child relationship. Parenting behaviors in the context of parent-child interactions have been shown to moderate the impact of genetically based temperament/disposition in the child. For example, parents who responded in firm but loving and sensitive ways ended up with children who, despite early difficulties with temperament and control, had fewer externalizing behaviors than those with the same tendencies but a different parenting approach. Genetic tendencies can become realized or not based on environmental factors, most notably parenting (Sameroff, 2009). Parenting behaviors seem to act as a trigger for expression of the genetic tendency. While genetics, contexts outside the family, and environmental factors all play roles in child socialization, therefore, specific parenting behaviors appear to mediate all of these to some extent throughout the lifespan (Collins et al., 2000).

Research indicates that, while there are a variety of child factors that impact problematic behaviors, parental discipline practices can either serve to alleviate or exacerbate these problems (Arnold et al., 1993). Specific elements of interaction, particularly parent emotional 
expressivity, seem to moderate the relationship between level of child's daily stress and constructive coping abilities. This improvement in child coping behavior positively impacts dynamics in the parent-child relationship as a whole (Valiente, Fabes, Eisenberg, \& Spinrad, 2004).

Research on parent-focused interventions provides insight into the ways in which parent characteristics and behaviors reduce the impact of child symptoms. Parent-focused interventions have been found to be efficacious in addressing a variety of psychosocial problems stemming from conditions such as ADHD, abuse and neglect, depression, anxiety, and conduct problems (Hoagwood, Burns, Kiser, Ringeisen, \& Schoenwald, 2001). Specifically in relation to autism, family-centered intervention, rather than purely child-oriented treatment approaches, has been identified in the literature as a best practice (Howlin, 2000; Levy, Kim, \& Olive, 2006).

Research on specific types of intervention in autism lends support for the idea that elements of parent-child interaction may mediate the effect of child autism symptom severity on the overall parent-child relationship. Intervention targeting parent behavior changes at the interaction level with the child may reduce the impact of child symptoms on the overall relationship. Studies have shown how parent-directed forms of intervention can be effective at creating changes in the parent-child relationship that then lead to developmental improvements for the child. Improving parent mood, for example, has been shown to make a difference in the quality of infant-parent interactions and subsequent child development (Field, 1998). Dyadic interventions with mothers and preemies have proved helpful in bolstering the development of intersubjectivity by improving attunement between parent and child (Meyer, Coll, Lester, Boukydis, McDonough, \& Oh, 1994).

Interventions aimed at creating change in parents and, thus, in parent-child relations have also been shown to be effective in reducing symptoms of autism and/or reducing the impact of 
symptoms on the parent-child relationship. Training mothers in mindfulness, for example, has caused significant reduction in maladaptive behaviors of their children with autism, without making direct attempts to impact the children themselves (Singh et al., 2006). Mothers involved in this study reported an increase in overall parenting satisfaction, increased satisfaction with their parenting skills, and an increase in mindfulness with their children. A program aimed at increasing parental responsiveness to their child with autism showed a positive impact on the child's social-emotional development (Mahoney \& Perales, 2003). An intervention designed specifically to reduce problematic behaviors in children with autism demonstrated that shifting parents from either an authoritarian or permissive style of parenting to a more authoritative style resulted in positive behavior changes in the child (Whittingham, Sofronoff, Sheffield, \& Sanders, 2009).

Aldred, Green, and Adams (2004) conducted a study designed to evaluate an intervention delivered only to parents of children with autism. Results showed that children increased significantly in reciprocal social interaction, social engagement, social rapport, social responses, and spontaneous initiation of social interaction as measured by the ADOS. These children also made significant improvements in language, with measurable increases in expressive and receptive vocabulary. Other studies have also shown that providing training to parents yields improvements in joint attention (Aldred et al., 2004; Jones, Carr, \& Feeley, 2006; Schertz \& Odom, 2007), communication (Symon, 2005; Vismara, Colombi, \& Rogers, 2009), schoolreadiness skills (Ozonoff \& Cathcart, 1998), shared engagement and problem solving (Wieder \& Greenspan, 2003), and reduced problematic behaviors (Whittingham et al., 2009; Sofronoff, Leslie, \& Brown, 2004). Findings such as these stress the importance of understanding social reciprocity as a two-way street, with change needed for both the child and those interacting with $\operatorname{him} /$ her (Gernsbacher, 2006). 
These studies present important evidence supporting the influence of parent behavior and cognition on child symptoms and, as a result, the parent-child relationship. Parents need information and support to enable them to have the courage to address their child's deficits and problematic behaviors, rather than allowing those to continue for fear of upsetting the child further (Howlin, 1998). Providing parents with a model for modifying themselves in ways that have nothing directly to do with the child's symptoms can provide a therapeutic milieu in which those symptoms can change (Singh et al., 2006). A number of beneficial outcomes for parents have been identified as a result of parent-directed treatment, including increased sense of parenting competence (Symon, 2005), increased parenting satisfaction (Jocelyn et al., 1998; Whittingham et al., 2009), increased parental efficacy (Whittingham et al., 2009), and a greater sense of control (Jocelyn et al., 1998).

Training parents of children with autism to interact with their child in specific ways has been successful at reducing symptoms regardless of initial symptom severity (Solomon, Necheles, Ferch, \& Bruckman, 2007). Therefore, the most important issue concerning autism treatment may be determining how to modify parent-child interactions in order to most effectively promote specific skill development given particular child and environment characteristics (Rogers \& Vismara, 2008). In order to understand more fully what influences symptoms for certain children with autism, it is important to identify how child symptom severity influences parents and responds to changes in the bidirectional context of relationships with them (Howlin et al., 2009).

\section{Summary of Literature that Defines the Theory}

The bidirectional model of child socialization is a recently developed construct in the realm of developmental psychology. Prior to 1960, the prevailing model in the field was unidirectional and emphasized the impact of parents on child behavior and development 
(Kuczynski, 2002). The focus of research was primarily on identifying certain absolute laws that governed individual behavior (Reis, Collins, \& Berscheid, 2000). Within this model parents were seen as the primary vehicle for socializing children into their culture, and the children were merely recipients of parental cognitive and behavioral influences. The first step in the shift from a unidirectional to bidirectional model of conceptualizing parent-child relationships occurred when research by Sears, Maccoby, and Levin (1957) uncovered intrinsic characteristics of children that impacted their behavior and the subsequent status of the parent-child relationship. These researchers concluded that a unidirectional approach to understanding parental impact on children was an oversimplification, and did not reflect the true nature of these relationships.

Bell (1968) was the first to officially champion a shift in conceptualization of parentchild relations from the traditional unidirectional model to a bidirectional model. In his landmark paper, Bell contended that a bidirectional model was required in order to recognize the influences of both parents and children on their mutual relationship and overall development of the child. He asserted that one needs only look at parents with their infants to understand the power of the child's influence over parent behaviors. An infant crying in distress has a strong and immediate effect on a parent's behavior, in that the parent will go to great lengths to cease the child's crying and elicit a happier affect. While the parent's behavior cannot be attributed solely to the child's influence, there is a definite impact on the parent's response to the child. A number of animal studies supported Bell's (1968) assertion that offspring are both influenced by and influence the behavior of their caregivers. In addition, research with human children and their parents also demonstrated the presence of specific parenting differences based on child behavior. Perhaps the most compelling evidence for his model of bidirectionality was research identifying specific differences in behavior for the same parent when engaged with different children (Yarrow, 1963). This made it clear that specific parenting behaviors could be 
explained more by the child's characteristics and behavior than by the parent's attitude or cognitions.

This early research on bidirectionality of parent-child interactions began laying the foundations for understanding how child impairments and disabilities specifically impact the parent and, thus, parent-child relations. Bell (1968) identified two specific sets of child features that significantly impact parents - impaired sensory motor development and behavior disorders (specifically, hyperactivity). In this same vein, Sameroff and Chandler (1975) began exploring bidirectional influences between parent and child behaviors in their studies of resilience. They found that there was not a direct correlation between specific child characteristics and outcomes. It appeared that certain parent factors mediated the impact of innate child characteristics on the child's overall development and outcomes.

Sameroff and Chandler (1975) also conducted research supporting the idea that child temperament contributed to parent behavior; specifically, that children with challenging temperaments and physical disabilities were more prone to suffer abuse at the hands of their parents than were their typical siblings. Based on this research, they expanded Bell's notion of bidirectionality to a transactional model whereby the child interacts with the overall caretaking environment, including parents, and both impact each other. In this expanded model, parents and children are constantly influencing each other over time through their interactions, similar to a dance where both partners are leading (Sameroff, 2009). Transactions are more than mutual influences, in that they involve the transformation of each participant and the relationship as a whole over time (Fogel, 2009). The central component of the transactional model is the emphasis on analyzing bidirectional, interdependent contributions of child and environment (Sameroff, 2009). This is most often and most easily analyzed in the context of parent-child 
relationships. The transactional model has become a more global application of the bidirectional model of child socialization.

This bidirectional model has become dominant in the fields of child development and socialization. Research by Harach and Kuczynski (2005) showed that parents readily recognize the contribution of child characteristics to their relationship with them. Their study examined parent perceptions of both their own and their child's influence on the parent-child relationship. Results demonstrated that parents clearly identified ways in which their children influenced parent-child interactions and relationships. Specifically, parents felt that their children contributed to strengthening the relationship by complying with parent requests and engaging in positive social interactions. They indicated that their children damaged the relationship by lack of compliance and challenging parent directives.

The evolution of research on bidirectional parent-child influences has led to widespread recognition that children actively influence their own development through their relationships with parents and others (Cummings, Davies, \& Campbell, 2000). Panksepp (1994) asserted that the infant's biological predisposition interacts with critical life experiences to affect the overall development of neural systems. Hasting's (2002) research on parenting stress, parent psychological distress, and child behavior suggests that current child behavior influences development and future behavior as a result of the impact on parents. His findings indicate that child behavior problems lead to parenting stress, which disturbs parenting behavior, which cycles back to increasing the child's problematic behaviors. This model has been used to investigate parent-child relationship elements and child development in Down Syndrome (Van Hooste \& Maes, 2003). A review of the literature concerning parents of children with Down Syndrome identified a number of ways in which parent-child interaction influenced development of the child with this condition. Certain child characteristics impact the responsiveness of parents, thus 
disrupting the synchrony of interaction between them. These children have characteristics that impact their own development via the transactional nature of their interactions with parents.

A significant body of literature on autism has arisen around this bidirectional model of development through relationships, especially through research related to human intersubjectivity. An awareness and understanding of relationships with others, called "intersubjectivity," is a key factor in the development of language and cognition. Babies are born with a drive to engage with the communication and emotional expressions of those around them. From within moments of birth, parents engage the child in interactions that develop a sense of connectedness as a result of meaningful social/intersubjective engagement (Hobson, 2004). This "innate intersubjectivity" makes infants especially attuned to the emotional states in other people (Fogel, 1993; Stern, 2002; Trevarten \& Aitken, 2001). Their brains are capable of much more than was once thought, and person awareness (versus object awareness) is central to development prenatally and beyond.

The ability to be socially and emotionally attuned is a uniquely human attribute, and one that begins early in infancy. There is an internal ability to combine perceptual input from multiple sources in order to achieve one's motives and intentions. The presence of this social intelligence is necessary, but not independently sufficient for children to develop psychosocially in ways that lead to and depend on cultural learning. Understanding of objects arises from engaging with others, and allowing more competent others to guide perceptions through their communication, cognition, and emotion (Bakeman \& Adamson, 1984). Cognition does not come first, as was once thought. Rather, cognition relies on social interaction to develop.

Communication, like cognition, has its roots in early intersubjective experiences. Social cognition, theory of mind, and pragmatics of speech are experience-dependent skills that have their foundations in early interpersonal experiences. Parent-child interaction is essential for the 
development of language, as it is the outcome of carefully attuned engagement over the course of early development. These interactions are comprised of a combination of child sociability, parental willingness and interest in parenting, and a cooperative awareness of each other. This leads children to understand the meaning of themselves, others, and the environment; and ultimately allows language development. By the end of the first year of life, children are able to engage fluidly in triadic interactions (me-you-it), share joint attention, and understand intentions of themselves and others. They can communicate in complex ways without using language, share arbitrary experiences and perceptions, and adapt to the intentions and actions of others (Trevarthen \& Hubley, 1978). By the end of the second year, children develop linguistic skills and competence with conventions of communication that allow for further cognitive growth in multiple directions (Tomasello, 2007).

Intersubjectivity is also critical for the development of self-regulation. Children learn to regulate themselves by first learning to regulate with others. Referenced in the literature as coregulation (Sroufe, 1996), this process includes borrowing the cognitive appraisal process and responses of the parent in order to learn how to appraise, process, and respond on one's own. It is this co-regulatory interaction with primary caregivers that leads to the development of selfregulation of actions and emotions. This is a major responsibility for parents to undertake with their children, and one that typically happens intuitively rather than intentionally.

The ability to develop intersubjectivity is rooted in the appropriate development of the neural structures of the brain and the core regulatory mechanisms within it, a process that begins prior to birth. Integration of neural systems must occur in order for infants to develop purposeful consciousness, and to cooperate with and learn from the actions of others. If these experiences are disrupted by a disorder on the part of child or parent, the result is that these skills develop later and are negatively impacted (Trevarthen \& Aitken, 2001). Child disorders, parental 
problems, environmental traumas, and other issues can impact the degree of emotional attunement between parent and child, thus influencing how the child develops motivation to engage in and respond to experiences.

Failure to engage in these early interactions based on intersubjectivity, or to benefit from them, leads to an impoverished conceptualization of oneself and others (Richer, 2001). This is the trajectory that is seen in autism, where the disorder creates disruption in the relationships between children and their primary caregivers to the point that typical development of self and other awareness fails to occur. This lack of awareness leads to a failure to identify the salient elements of environments and interactions, instead becoming focused on less salient or irrelevant aspects of them (Sherratt \& Donald, 2004). It is this failure to develop a full understanding of self and others and, therefore, attend to meaningful aspects of the environment that leads to the deviant path of development seen in the constellation of symptoms used to describe autism (Hobson, 2004; Ruble et al., 2008).

\section{Literature Based Description of Research Variables}

\section{Parent-Child Interaction}

Interactions are the building blocks of relationships; and the essential nature of the relationship can be found in the moment-to-moment interactions that occur between the partners involved (Kuczynski, 2003). It is critical to understand the dyadic nature of parent-child interactions. The defining feature of interaction is influence, in that each partner's behavior exerts influence over the other's partner's behavior that follows. It is not one partner's characteristics that define the interaction, but the interactions of both partners' characteristics that define the overall interaction between the two (Reis et al., 2000).

The advent of parent-child interaction analysis occurred around the time that video recording devices became available to researchers. This new technology allowed for the 
moment-by-moment capturing and analysis of specific interactions between parent and child in a way that had not been possible before (Maccoby, 1992). A number of prominent researchers in the area of development have identified core components of parent-child interactions, including the following types: responsivity, shared understandings, joint attention, role assumption, awareness of intentions, shared emotional states, emotional expression, initiation strategies, connections of verbalization to action, eye gaze, turn-taking, verbal and nonverbal communication, mood, and coordination and flow of actions (Fogel, 1993; Humber \& Moss, 2005; Stern, 2002; Trevarten \& Aitken, 2001). It is the combination of these elements over the course of engagement that defines the patterns of interaction between parent and child.

\section{Parent-Child Relationship}

Relationship can be defined as the existence of interdependence between two individuals. Close relationships, such as those between parents and children, are identified by the level of endurance and the strength of connections between the partners involved (Harach \& Kuczynski, 2005). While parent-child relationships are the product of ongoing interactions, they are not simply the accumulation of these interactions. Interactions influence and build on one another over time, and as a result each interaction changes the next. Therefore, relationships between parents and children are dynamic systems that evolve over time as interactions influence the overall status of their relationship with each other (Reis et al., 2000). Relationships are also driven by the developmental needs of the participants, and shifts in development generally do not occur without changes in close relationships (Laursen \& Bukowski, 1997).

A number of specific components have been identified in the literature concerning parent-child relationships. Bugental (2000) identified attachment, reciprocity, and hierarchy of power as elements requiring consideration in the ongoing relationships between parents and children. Aspects of permanence, power, gender, closeness, level of interdependence, and 
stability have also been raised as identifiable components of these relationships (Laursen \& Bukowski, 1997). Stress level and amount of available support for parents has also been recognized as a component of parent-child relationships (Sidebotham, 2001). Baumrind's (1966) research on parenting styles has also highlighted some important characteristics of parent-child relationships including limit setting, control, level of autonomy, expectations, and communication.

\section{Autism Symptom Severity}

The DSM-IV-TR (APA, 2000) identifies three major areas of impairment resulting in a diagnosis of autism. The first is qualitative impairment in social interaction, including impaired nonverbal behaviors such as eye gaze and gestures, inability to develop appropriate peer relationships, and lack of social reciprocity. The second area is qualitative impairment in communication, including delay in or lack of spoken language, impaired conversation skills, and lack of developmentally appropriate spontaneous or make-believe play. The final area of impairment is the presence of restricted and repetitive behaviors that are stereotyped in nature, including rigid adherence to non-functional routines, preoccupation with specific parts of objects, and repetitive motor mannerisms.

While these categories of symptoms describe some of the outwardly apparent behaviors and symptoms seen in individuals with autism, current research reflects a more targeted understanding of the foundational developmental deficits that result in these more obvious symptom patterns. These root issues that create the pervasive impairments seen in autism can be referred to as the core deficits of this disorder (Sigman et al., 2006). It is these core deficits that define the disorders currently separated into three distinct categories in the DSM-IV-TR (2000), namely Autistic Disorder; Asperger's Disorder; and Pervasive Developmental Disorder Not Otherwise Specified. Conceptualizing these disorders as occurring on a continuum of universal 
symptoms with varying severities is gaining popularity in the field, and may lead to some significant changes in the upcoming version of the DSM (Swedo, 2009). Using this conceptualization, individuals who have autism all exhibit the same constellation of symptoms to varying degrees, from mild to severe. It is this paradigm shift that makes investigation of severity-related aspects of the disorder relevant for the furtherance of the field at this time.

Autism has been described as a disturbance in the emotional exchanges that occur first between infants and mothers, and that continues as the child ages - a lack of reciprocal adaptation to others' rhythms of communication and interaction (Trevarthen et al., 1998). One of the earliest deficits to arise in autism is failure to initiate joint attention with others (Sigman \& Ruskin, 1999). Joint attention is the non-verbal process through which individuals draw each other's attention to the same thing for the purpose of sharing awareness and perceptions. It requires intention on the part of both partners to create shared meaning to a common stimulus - $\mathrm{a}$ triadic interaction among "you, me, and it" (Mundy \& Willoughby, 1998). There is not only a desire to bring another's attention to something, but also a positive affect that goes beyond the skill of making something known to another (Mundy, Kasari, \& Sigman, 1992). Both initiation of joint attention and response to joint attention attempts by others are significantly impaired in children with autism (Bruinsma, Koegel, \& Koegel, 2004). Inherent in joint attention deficits are a reduction in use and understanding of nonverbal communication such as eye contact, facial expressions, and gestures. A lack of positive affect connected to joint attention attempts has also been observed in this population (Mundy et al., 1992). These are all components of communication that precede verbal communication (Tomasello, 2005), and are significantly impaired in individuals with autism (Mundy \& Crowson, 1997).

Self-and-other awareness is also considered a core deficit of the disorder. Lack of selfawareness emerges first not as a problem with the physical self (developing an awareness of the 
difference between myself and the physical world), but with the interpersonal self (awareness that others are viewing me as a separate entity). This lack of awareness of self in relation to others creates a deficit in awareness of others, as this type of awareness depends on the development of self-awareness in order to transpire (Travis \& Sigman, 1998). Imitation is a skill that develops within the first year in typically developing infants, and depends on self-and-other awareness. More than simply copying actions, true imitation involves understanding the intentions of the other person. Therefore, deficits in imitation are also considered a fundamental deficit of autism (Charman et al., 1997; Liebal et al., 2008; Williams, Whiten, \& Singh, 2004).

Deficits in experience-sharing are also core deficits of autism. Gutstein and Whitney (2002) noted that secure attachment, instrumental social learning, and experience-sharing in relationships are all elements required for social competence. While the first two do not appear to be deficits for individuals with autism, the last is lacking. Experience-sharing requires reciprocal enjoyment and enthusiasm with others, coordinating emotion and relationships, and engaging in ongoing maintenance and repair when breakdowns occur. Evidence of these skills is seen in infants as young as nine months old. Typically developing infants at this age make initiations for their partners to join them in familiar games, and are able to clarify their nonverbal communication in order to make repairs when their partner fails to respond appropriately (Ross \& Lollis, 1987).

Verbal speech delay has been shown to be insignificant in later outcomes for individuals with autism, indicating that it is more than just the presence of verbal language that determines developmental progress (Mayes \& Calhoun, 2001). The idea of impaired experience-sharing describes the other elements that are lacking in individuals with autism such that they are unable to develop relationships commensurate with their age and ability level. These deficits can be conceptualized as occurring in the areas of social motivation, social referencing, and co- 
regulation with others. It is this combination of cognitive impairment (the inability to form representations of self and others) and affective impairment (the lack of motivation/capacity to share attention) that creates the fundamental social and communication problems seen in this population (Charman, 2005).

Deficits in spontaneous symbolic play are also well documented in the autism literature (Mundy et al., 1987; Ungerer \& Sigman, 1981; Wing et al., 1977). While children with autism have shown the ability to engage in some forms of pretend play when it is specifically taught and elicited (Lewis \& Boucher, 1988), spontaneous play behavior is generally not observed in this population. Play behaviors observed in autism are generally limited, repetitive, and objectoriented. They also typically do not include others in meaningful roles, and the ability to switch roles and role actions is rare (Brown \& Whiten, 2000). It is important to note that the ability to play stems from the development of a variety of social-emotional and cognitive abilities. Social play develops in a transactional way between parents and children from a very early age. In autism, the failure to develop initial social relationships even as young as infancy impacts ongoing social-emotional development. It is because of these relational underpinnings that play cannot be effectively taught as a series of discrete skills, but must be the outgrowth of more basic social and cognitive discoveries (Jordan, 2003).

A number of tools have been developed to assess the presence of autistic symptomology. However, few are designed to identify a wide range of severity among the various symptom clusters that define autism. The Autism Diagnostic Observation Schedule (ADOS) (Lord et al., 2002) is widely considered the gold standard instrument for identifying symptoms along the spectrum. Observations of responses to a number of specific activities are coded, with scores identifying the presence of symptoms consistent with a diagnosis of "autism," "autism spectrum," or "non-autism (Gotham et al., 2007)." Even in assessment of children as young as 
toddlers, the ADOS accurately distinguishes children with features necessary for the diagnosis from those without (Ventola et al., 2006). This tool, either in isolation or in combination with other tools, is utilized in research concerning autism to confirm the diagnostic classification of study participants.

Recently revised algorithms for the ADOS allow for better specificity in classification of symptoms (Gotham et al., 2009), as well as increased alignment between the various modules used with participants of differing ages and functioning levels (Gotham et al., 2008). Scores are calibrated to yield an autism severity metric. Research has shown that this calibrated score is better at identifying severity of symptoms independent of participant demographics than the ways scores were calculated on the previous versions of the ADOS (Gotham et al., 2009). These revisions correspond to the growing trend of conceptualizing autism as a core set of symptoms occurring along a spectrum of severity, as opposed to a group of separate and distinct diagnoses.

Another tool used in the evaluation of autism, including research studies, is the Social Responsiveness Scale (SRS) (Constantino \& Gruber, 2005). This survey tool conceptualizes autism along a continuum of severity among several social, communication, and behavioral symptoms. Results indicate the likelihood that an autism spectrum disorder is present, and indicate the severity of specific symptom clusters. It is possible, therefore, to identify a participant's combined symptoms score in addition to the severity of symptoms in specific areas of communication, socialization, and behavior (Constantino et al., 2000). This method of measuring specific autistic symptoms by degrees of severity is also in alignment with current research related to autism symptoms and diagnosis.

\section{Literature Related to the Method and Differing Methodologies}

Parent-child interaction and relationships have been researched using a variety of methodologies including quantitative, qualitative, and mixed methods designs. Experimental 
methods have also been used to study these constructs. All of these methods have also been used to research various aspects of autism symptoms and interventions. Much of the research investigating parent-child interaction and relationships in autism has utilized small sample sizes with correlational designs.

Many studies have utilized quantitative methods to investigate interaction dynamics and child characteristics. A common aspect of these studies is the use of videotaped footage of parent-child interactions to analyze specific variables. The field of infant, child, and parent research has an extensive history of utilizing videotaped footage to analyze child development in the context of parent-child interaction (Trevarthen \& Aitken, 2001). This tradition has been extended to the field of autism, with a wide range of studies utilizing videotaped interactions for various types of analysis.

Siller and Sigman (2002) studied the connection between child language outcomes and caregiver behaviors utilizing a correlational approach. Coded videotape footage was used to analyze caregiver behaviors, and findings indicated a strong correlation between these two variables. A longitudinal study by the same researchers (Siller \& Sigman, 2008) analyzed child symptoms at an early age and interactive experiences with parents, captured via structured videotaped observations, in order to better understand variability in outcomes of these children. Correlational analysis and multilevel models, conducted within and between subjects over the longitudinal time frame, found that all aspects of mother-child synchronization predicted future child language gain.

In their study of child attachment characteristics in typically developing children and mother-child interaction, Humber and Moss (2005) found significant correlations between severity of child attachment problems and quality of interaction. This study also utilized structured videotaped interactions to gather data pertaining to aspects of interaction. Ruble and 
colleagues (2008) used correlations and regression analysis to identify interaction of caregiver characteristics and social interaction behaviors in young children with autism. Data for this study was also collected via specific activities captured on videotape.

Qualitative research has also been conducted in the area of parent-child relationships and autism, with the focus primarily on the experiences of parents in relation to their children. Woodgate, Ateah, and Secco (2008) examined the experiences of parents of children with autism via interviews. They utilized hermeneutic phenomenology to gain an understanding of each family’s “lived experience." A phenomenological study by Cashin (2004) identified several salient themes in the relationships between parents and their children with autism.

Other methodologies have also been utilized in the realm of autism and parent-child interaction and relationships, although with less frequency than purely quantitative and qualitative research. Case studies have been conducted to identify significant elements related to autism and parent-child interaction. One such study by Hedenbro and Tjus (2007) used a mixedmethods approach to describe parent-child interaction between a girl with autism and her parents. They made both quantitative and qualitative observations using videotaped interactions at 3, 9, 18 , and 48 months of age, and compared this data to other families with typically developing children at those ages. Extensive interview data was also collected for qualitative analysis to complement the observations conducted by the researchers. A unique Q-methodological study (DeMol \& Buysse, 2008) was also found in the literature regarding the bidirectionality of parentchild interaction. Results identified cultural understanding of both parents and children surveyed in relation to their experiences of interacting with and exerting influence upon one another.

\section{Summary}

Bidirectionality has been identified as an important characteristic of parent-child interactions and relationships, meaning that both parents and children exert influence over the 
other (Harach \& Kuczynski, 2005). Parent traits and behaviors impact the child, and child traits and behaviors impact the parents; thus, a bidirectional dynamic is created. Literature on human intersubjectivity, which has grown out of the bidirectional model of socialization, has solidified understanding of how development occurs through relationships with parents and others. Research has shown that various child characteristics, including symptoms of disabilities, significantly impact the child's ongoing development by disrupting parent-child interactions. This has implications for the consideration of child autism symptoms and their impact on parentchild interactions and relationships. A limited amount of research has been conducted on the ways in which child symptoms impact relationships with parents; and results indicate that while attachment is generally not affected, other elements of interaction and relationships are negatively impacted. The effect of child symptom severity on moment-to-moment interactions and the overall relationship with parents has not yet been explored, and constitutes the focus of this proposed study. Chapter three provides a detailed description of the research design and methodology proposed to examine the research question and hypotheses formulated from the problem discussed in Chapter One. 


\section{Chapter 3: Research Method}

The study aimed to improve understanding of how autism symptom severity impacts parent-child interaction and relationships. A quantitative methodology was used to investigate the extent to which degree of symptom severity corresponds to variations in aspects of both interaction and relationships. This chapter describes the methods used to research the study hypotheses. A description of study design, instrumentation, participants, data collection methods, and data analysis techniques is also included. The main purpose of this study was to determine how symptom severity, parent-child interaction, and parent-child relationships are related, in order to improve understandings of how this may impact child development overall.

\section{Research Design and Approach}

In this study, I examined autism symptoms of children, and relationships and interactions between these children and their parents. Results of this study are descriptive in nature and are intended to serve as a point of reference for potential future studies in this area. Results from the DCS and the PCRI are the dependent variables. The scored domains on the DCS include: coordination, communication, appropriate role assumption, emotional expression, responsivity/sensitivity, tension/relaxation, mood, enjoyment, and an overall rating. Scales on the PCRI include: parental support, satisfaction with parenting, involvement, communication, limit setting, autonomy, and role orientation. Autism symptom severity, indicated by the calibrated autism severity metric on the ADOS, is the independent variable. The study approach is comparative, not experimental in nature, and I examined parent reports and coded videotapes of parent-child interaction for children with various autism symptom severity levels.

The correlational approach was appropriate for this study because videotaped interactions and parent reports were utilized to determine the presence of a relationship between independent 
and dependent variables. Experimental design was not required, as participants were not randomly assigned to specific groups for the purpose of variable manipulation. Rather, scores on the DCS and PCRI reflect aspects of interaction and the overall relationship that parents and children currently experience.

\section{Setting and Sample}

\section{Participants}

The participants in this study were a convenience sample of children ages 4 through 15 years with a diagnosis of autism, and the family-identified primary parent. For two-parent families, data were collected from whichever parent the family indicated as primarily responsible for the child's care. For single-parent families, data were collected from the custodial parent. Participants were recruited from various autism organizations throughout West Michigan. Participants were selected for the following reasons: (a) they were an accessible population; (b) they fit the age parameters of all instruments utilized; (c) they had a diagnosis that fits the symptoms of interest in the study.

\section{Sample Size Justification}

The study utilized a multivariate regression with one predictor variable. G*Power was used to determine the sample size needed for this study. For a linear regression, with an alpha level set at .05, 25 participants yielded a power of .80, with a large effect size of .35 (Buchner, Erdfelder, \& Faul, 1997).

A large effect size was deemed appropriate for this study, given previous literature in the realms of symptom severity as well as parent-child interaction and relationships. Siller and Sigman (2002) investigated caregiver behavior in relation to child language development in children with autism for 25 parent-child dyads. They found a large correlation between caregiver synchronization and child gains in language, with Pearson $r$ values ranging from 46 to 
.79 for the majority of the correlations. In their study of 34 mother-child dyads, Young and Hauser-Cram (2006) found significant correlations and large effect sizes between parent responses to distress and child mastery motivation and cognitive performance. All of the children in the study were born preterm and diagnosed with disabilities, and correlations of $r=.40$ and .42 were reported. A recent investigation of various aspects of relatedness between parents and children with autism utilized 30 dyads and, on average, found correlations of $r=.60$ between ADOS scores (measuring symptoms severity) and aspects of parent-child interaction (Hobson et al., 2008). The outcomes of these studies suggested that it was reasonable to expect large effect sizes for the proposed correlations in this study, thus justifying the sample size of 25 participants.

\section{Procedures}

Participants were selected based upon the participant eligibility criteria. A letter inviting participation and explaining informed consent (Appendix A) and informed assent (Appendix B) was sent to each potential family, indicating the purpose of the study, as well as participation details. Once consent forms were signed and returned, a numeric code was assigned to the family and all corresponding paperwork in order to preserve confidentiality. The family was then scheduled for their taped activity session and ADOS administration. I used the child verbal assent script (Appendix C) to obtain verbal assent from children under age 7 years, administered the ADOS, and facilitated the taped activity session. The parents were given the PCRI to complete and return at their scheduled appointment time.

The taped activity session occurred within the clinic setting, and consisted of at least a 10-minute and not more than a 20-minute time period in which the primary parent and child were provided a variety of age-appropriate materials and toys with which to play (Appendix D). Materials included the following types: balls, active games, board/card games, blocks, puzzles, bean bags, and other items as appropriate for the age and developmental level of the child. The 
parent and child were instructed to get comfortable and to use the materials together in whatever ways they wished. Parents were instructed to set whatever limits and boundaries they would with the child at home.

Once data collection was completed, the videotaped activities were coded using the DCS. Dr. Jessica Hobson at the Tavistock Institute in London was a research partner, and assisted with coding the DCS. This helped prevent bias in the coding and study outcomes. The ADOS and PCRI were hand scored. All protocols and videotape footage were labeled with a numeric code indicating the items attached to each participating family. The family's name does not directly appear on any of the testing protocols or video footage.

\section{Instrumentation and Materials}

\section{Demographics}

A demographic questionnaire (Appendix E) gathered information from participants regarding parent and child characteristics that may be confounding variables in the study. Parent and child age, gender, ethnicity, and level of education were collected. Information regarding the child's diagnosis, age of diagnosis, and any notable medical conditions and health history was also requested. Finally, information about the family system was requested, including the individuals living with the child in the home, ages of siblings, and approximate amount of time spent with parents each day. Families with more than one parent in the home also indicated which of the parents was to be considered the primary parent for the purpose of the study.

\section{ADOS}

The Autism Diagnostic Observation Schedule (Lord et al., 2002) is considered the gold standard for evaluating and diagnosing autism spectrum disorders across all ages, developmental levels, and communication skills. Appropriate for toddlers through adults, this test requires approximately 30-45 minutes to administer. Extensive training and practice is required in order 
to administer and score this measure correctly. I have been trained to administer, score, and interpret this instrument, and have many years of practice doing so in clinical and research settings.

The ADOS is a standardized assessment of communication, social interaction, behavior, sensory stereotypies, and play or imaginative use of materials. One of four modules is administered based on the individual's developmental and language level. Structured activities and materials provide standard contexts in which social interactions, communication, and other behaviors relevant to autism spectrum disorders are observed. Items are scored on a scale of 0 (nonautistic qualities) to 3 (severe autistic qualities) in the areas of Social Affect and Restricted, Repetitive Behaviors. The scores from these two areas are then combined into one total score, where the lowest possible score of 0 indicates an absence of autistic characteristics and higher scores indicate increased presence of autistic features. A calibrated severity score, called the autism severity metric, is then calculated to identify severity of symptoms independent of participant demographics. This metric, ranging from 1 to 10 , allows for standardized comparison of total scores across modules. A severity metric score of 1-3 is considered "nonspectrum," a severity metric score of 4-5 is considered "autism spectrum disorder," and a severity metric score of 6-10 is considered "autism." This method of scoring is a departure from the current ADOS manual, but reflects current research conducted by the test authors (Gotham et al., 2009). They have developed this updated algorithm for scoring (Appendix F), and gave permission for its use in the context of this study (Appendix G).

The ADOS has undergone extensive standardization and validation processes. Originally, the instrument was standardized using a population of 381 children referred for autism evaluation. ADOS results were compared to diagnostic impressions of clinicians, as well as other standardized measures of autism including the Autism Diagnostic Interview and the 
Childhood Autism Rating Scale. Diagnostic consistency ranged between $80 \%$ and $90 \%$ for ADOS scores in comparison to clinical impressions and other diagnostic measures. Each module was also standardized, and has strong reliability and validity for assessing symptoms in the age group and language level for which it was developed. The newly developed scoring algorithm, including the autism severity metric, has also undergone rigorous psychometric evaluation. A dataset of 1,415 individuals with and without autism was used to determine the appropriateness of this new scoring system across age and language levels. It was determined that, with this new scoring protocol, verbal IQ accounts for only $10 \%$ of the variance in ADOS severity scores, as opposed to the previous system, in which $43 \%$ of the variance was accounted for by IQ. Therefore, the new calibrated metric is more consistently able than the previous scoring system to measure autism severity separate from verbal ability. Use of the tool in this study contributed to the research concerning this new scoring algorithm and severity metric.

\section{DCS}

The Dyadic Coding Scale (Appendix H) was developed by Humber and Moss (2005) to address the lack of a rating scale designed to assess qualitative aspects of parent-child interaction for school-age children. The coding system measures specific patterns of interaction between parent and child based on patterns seen in typical child development and attachment. Nine domains are rated on a scale of 1 to 7 , indicating the quality of the following aspects of interaction: coordination, communication, partner roles, emotional expression, responsivity/sensitivity, tension/relaxation, mood, and enjoyment. An overall rating is also assigned based on the overall quality of parent-child interaction observed. Lower ratings indicate poor interaction quality, while higher ratings indicate high quality interactions.

This tool was designed for and used within a study analyzing school-age attachment and mother-child interaction. The study involved 121 mother-child dyads with which to pilot the 
measure. Coding by raters blind to participant information demonstrated inter-rater reliability ranging from .62 to .75 for coded videotape interactions. Hobson et al. (2008) have established a precedent of using the DCS in studies of children with autism and their parents. Specifically, they have used the DCS to examine changes in parent-child interaction over time as a result of specific intervention. Inter-rater reliability in their study was deemed adequate, ranging from .57 to .86 for the various DCS subscales. While not commercially available, permission for use of this tool in the context of this study was granted by the author (Appendix I). This study contributes to the body of research concerning this instrument and it's usefulness in quantifying specific aspects of parent-child interaction.

\section{PCRI}

The Parent-Child Relationship Inventory (Gerard, 1994) is a survey tool for parents of children ages 3 through 15 years. Taking approximately 15 minutes to complete, this inventory assesses parent views on parenting and aspects of the parent-child relationship. The seven scales include: parental support, satisfaction with parenting, involvement, communication, limit setting, autonomy, and role orientation. Two validity scales assist in determining the presence of inconsistent or untruthful response patterns. Items are rated on a scale of 1 (strongly agree) to 4 (strongly disagree), yielding raw scores, $T$-scores, and standardized scores for each scale. Higher scores indicate more positive parent-child relationships. Separate scoring sheets and norms are provided for mothers and fathers.

This measure was standardized on over 1,100 parents across the United States, though Black and Hispanic families were under-represented. Reliability, as determined by internal consistency, had a median alpha of .82 . The mean test-retest correlations were .81 . Validity of this tool is high for each individual scale as compared to clinical impressions and other standardized measures. However, there are significant intercorrelations between some of the 
scales, making it questionable whether each measures unique constructs as opposed to having redundancy in the constructs measured. This tool was appropriately used in this study as it allows for analysis of more global aspects of the parent-child relationship, as opposed to the more specific moment-to-moment components of interaction analyzed through the DCS.

\section{Data Collection and Analysis}

All data were analyzed using SPSS version 17.0 for Windows. A number of descriptive statistics were generated, including frequencies and percentages as well as means and standard deviations. Frequencies and percentages were conducted for categorical or nominal data.

Frequency indicates the number of participants that fit into a given category, while percentage is the percent of the sample that corresponds with the given category. Means and standard deviations were calculated for all interval/ratio data. To determine the arithmetic mean of the variables, the sum of the scores is divided by the number of scores. Standard deviation measures the range of values in the data set, which is also known as the statistical dispersion. If the value of data points are close to the mean value, then the standard deviation is close to zero, as it does not stray far from the norm (Howell, 1992).

Research Question 1

RQ1: Does autism symptom severity, as measured by the Autism Diagnostic Observation Schedule (ADOS), predict parent-child relationship, as measured by the Parent Child Relationship Inventory (PCRI) and parent-child interaction, as measured by the Dyadic Coding Scale (DCS)?

$\mathrm{H}_{\mathrm{a}}$ Autism symptom severity, as measured by the Autism Diagnostic Observation Schedule (ADOS), predicts parent-child relationship, as measured by the Parent Child Relationship Inventory (PCRI) and parent-child interaction, as measured by the Dyadic Coding Scale (DCS). 
To examine research question 1, a multivariate regression was conducted. Multivariate regression is appropriately utilized when research aims to predict several dependent variables from one or more predictors (Stevens, 2009). The logic and computation used in multivariate regression is similar to multiple regression. In the case of research question 1 , two separate regressions could have been conducted to examine the prediction of autism symptoms severity on parent-child relationship and parent-child interaction. However, the use of a multivariate regression allowed for the simultaneous comparison of the relationships between the predictor and each dependent variable. The hypothesis tested was the joint linear effect of the predictor variable on both criterion or response variables.

The $F$ test was used to assess whether the independent variable (ADOS score) predicted the dependent variables (PCRI score and DCS score). Parent-child relationship was investigated on eight dimensions (level of parent support, parenting satisfaction, autonomy provided to the child, degree of involvement, parenting style, quality of communication, and parenting role orientation). Parent-child interaction was investigated on seven dimensions (coordination, communication, appropriate role assumption, emotional expression, responsivity/sensitivity, tension/relaxation, mood and enjoyment). $R$-squared — the multiple correlation coefficient of determination - is reported and used to establish the degree to which variance in the dependent variables can be attributed to the independent variable. The $t$ test was used to determine the significance of the predictor, and beta coefficients were used to identify the amount of prediction. For a significant predictor, every one unit of increase in the predictor increases or decreases the dependent variable by the number of unstandardized beta coefficients.

Multivariate regressions include a number of assumptions, including: normality of the residuals, homogeneity of variance, common covariance structure, and independent observations. 
Graphs and scatterplots of the residuals will be used to assess normality. Leven's test (Morgan, Leech, Gloekner, \& Barrett, 2007) was used to assess homogeneity of variance. Given that there is only one predictor, assessment of multicollinearity among predictors was unnecessary (Stevens, 2009).

\section{Protection of Participants' Rights}

The possible effects on the participants in this study were carefully appraised to ensure maximum safety and confidentiality. All participants received consent forms outlining study procedures, participant requirements, confidentiality issues, the voluntary nature of the study, potential risks and benefits of participation, and contact information for the researcher and her advisor in the event that specific questions should arise. Participants were also be informed of their right to withdraw from the study at any time. There were no physical safety risks or benefits from this study. In addition, there were no potential benefits or risks related to symptoms, as no treatment was applied or withheld for the purpose of the study. There was a potential for child participants to become upset when engaging in play activities in the clinic environment and parents were instructed to manage this in whatever way they felt best for the child. It was also possible that parents could experience some mild upset when completing survey tools, as they were required to reflect on aspects of their child's deficits as well as the status of their relationship with their child. Participants were instructed to refrain from completing any elements of the study protocol that created what they felt was unmanageable distress for themselves or their children.

Participant confidentiality was maintained via a numeric coding system. Every parentchild dyad was assigned a numeric code at the outset of their participation, and this code was used to identify each protocol and video footage associated with them. The parent and child name only appears on the signed consent forms, and originals of these forms have been retained 
to confirm informed consent. While parents signed giving consent, child participants who were capable provided assent. All records are confidential, with only the researcher and research assistants having access. Study protocols have been maintained in a locked file cabinet, and video footage is stored on a secure password-protected server in my office.

\section{Summary}

In this quantitative nonexperimental study, I investigated the influence of autism symptom severity on parent-child interaction and relationships. Demographic information about participants was gathered via questionnaire. The independent variable, autism symptom severity, was measured using the ADOS. Dependent variables were measured using the DCS for parentchild interaction, and the PCRI for parent-child relationships. A convenience sample of 25 participants was acquired from various autism organizations in West Michigan. Multivariate regression was used to analyze data in relation to the proposed research question. Results help expand understanding of the ways in which autism symptom severity impacts parent-child interaction and relationships. 


\section{Chapter 4: Results}

The purpose of this quantitative study was to investigate the impact of autism symptom severity on parent-child interaction and relationships. Specifically, this study was conducted to answer the research question: Does autism symptom severity, as measured by the Autism Diagnostic Observation Schedule (ADOS), predict parent-child relationship, as measured by the Parent Child Relationship Inventory (PCRI), and parent-child interaction, as measured by the Dyadic Coding Scale (DCS)? This hypothesis was tested through multivariate regression analysis. This chapter summarizes the results of the analysis and gives description of the participants sampled.

\section{Demographic Characteristics of the Sample}

A total of 25 children with autism and their primary parents participated in the study and completed the survey instruments and activities successfully. Of those who responded, six children (24.0\%) were female and 19 children (76.0\%) were male. Table 1 summarizes the demographic characteristics of the child participants. 
Table 1

Demographic Characteristics of Child Participants

\begin{tabular}{|c|c|c|}
\hline Characteristic & $n$ & $\%$ \\
\hline \multicolumn{3}{|l|}{ Gender } \\
\hline Male & 19 & 76.0 \\
\hline Female & 6 & 24.0 \\
\hline \multicolumn{3}{|l|}{ Race } \\
\hline African American & 1 & 4.0 \\
\hline Hispanic & 1 & 4.0 \\
\hline Caucasian & 22 & 88.0 \\
\hline Asian & 1 & 4.0 \\
\hline \multicolumn{3}{|l|}{ Parent Participant } \\
\hline Mother & 20 & 80.0 \\
\hline Father & 5 & 20.0 \\
\hline
\end{tabular}

The ethnic breakdown of child participants was as follows: African American 4\%, Hispanics 4\%, Caucasian 88\%, and Asian 4\%. The majority of participant families listed the mother as the primary parent, with mothers comprising $80 \%$ of the parent participants and fathers $20 \%$.

The age range of child participants was between 4 years and 14 years. Table 2 presents the means and standard deviations for child participant's age. The minimum age was 4 , and the maximum age was $14(M=7.36, S D=2.47)$. 
Table 2

Means and Standard Deviations on Child Participant Age

\begin{tabular}{lccc}
\hline & $n$ & $M$ & $S D$ \\
Age $\quad 25$ & 7.36 & 2.47 \\
\hline
\end{tabular}

\section{Data Screening}

Prior to analysis, data were screened to ensure complete and accurate completion of instruments. All participants completed every survey item and assessment activity required for the study, and no missing responses were noted on any of the instruments. PCRI responses were screened for validity via the two validity scales, Social Desirability and Inconsistency Indicator, provided in the survey manual. The Social Desirability scale measures the presence of response patterns indicating the respondent's desire to portray his/her situation in an overly positive light. Scores of 9 or less invalidate the protocol based on overly positive responses, and no participants received Social Desirability scores of 9 or less. The Inconsistency Indicator measures the possibility that the respondent has provided answers in an inconsistent, inattentive, or random manner. Scores of 2 or higher indicate the presence of inconsistent response patterns, and none of the participants received an Inconsistency Indicator score of 2 or above. Therefore, all participant PCRI protocols were considered valid.

\section{Overview of Design and Procedures}

Autism symptom severity, parent-child interaction, and parent-child relationship were assessed for each participant. Parent participants completed a survey instrument along with a 
demographics questionnaire. Parent and child participants also completed a coded play-based observation, and child participants completed an assessment of autism symptom severity. The survey was the PCRI, which measured parent-child relationship and provided scores for seven subscales. The seven subscales measured support, satisfaction, involvement, communication, limit setting, autonomy, and role orientation. The subscale Means and $S D$ for the PCRI were as follows: $\operatorname{support}(M=48.80, S D=6.22)$, satisfaction $(M=48.28, S D=7.93)$, involvement $(M=$ 44.32, $S D=7.28)$, communication $(M=35.44, S D=7.72)$, limit setting $(M=48.60, S D=9.22)$, autonomy $(M=51.12, S D=9.67)$, role orientation $(M=51.88, S D=8.90)$. The subscale score ranges for parent-child relationship were as follows: support ranged from 36 to 59, satisfaction ranged from 33 to 66,23 to 53 for involvement, 21 to 53 for communication, 23 to 69 for limit setting, 24 to 70 for autonomy, and 31 to 64 for role orientation.

The play-based observation was coded using the DCS, which measured parent-child interaction and provided scores for nine subscales. The nine subscales measured coordination, communication, partner roles, emotional expression, responsivity, tension/relaxation, mood, enjoyment, and overall interaction. The subscale Means and $S D$ for the DCS were as follows: coordination $(M=4.04, S D=1.42)$, communication $(M=3.76, S D=1.71)$, partner roles $(M=$ 3.80, $S D=1.08)$, emotional expression $(M=3.40, S D=1.78)$, responsivity $(M=3.60, S D=$ $1.26)$, tension/relaxation $(M=3.96, S D=1.51)$, $\operatorname{mood}(M=4.00, S D=1.58)$, enjoyment $(M=$ 3.84, $S D=1.49)$, and overall $(M=3.84, S D=1.37)$. The subscale score ranges for parent-child interaction were as follows: coordination ranged from 2 to 6 , communication ranged from 1 to 7 , 2 to 6 for partner roles, 1 to 7 for emotional expression, 2 to 6 for responsivity, 1 to 7 for tension/relaxation, 1 to 7 for mood, 1 to 6 for enjoyment, and 2 to 6 for overall interaction.

The ADOS measured child autism symptom severity, and provided a calibrated severity score for each participant. The range of ADOS severity scores was from 4 to $10(M=6.88, S D=$ 
1.51). Table 3 presents the means and standard deviations for each instrument and their individual scales.

Table 3

Means and Standard Deviations for ADOS and the Scales of DCS and PCRI

\begin{tabular}{|c|c|c|}
\hline Variable & $M$ & $S D$ \\
\hline ADOS & 6.88 & 1.51 \\
\hline \multicolumn{3}{|l|}{ DCS } \\
\hline Coordination & 4.04 & 1.43 \\
\hline Communication & 3.76 & 1.71 \\
\hline Partner roles & 3.80 & 1.08 \\
\hline Emotional expression & 3.40 & 1.78 \\
\hline Responsivity & 3.60 & 1.26 \\
\hline Attention/relaxation & 3.96 & 1.51 \\
\hline Mood & 4.00 & 1.58 \\
\hline Enjoyment & 3.84 & 1.49 \\
\hline Overall & 3.84 & 1.37 \\
\hline \multicolumn{3}{|l|}{ PCRI } \\
\hline Support & 48.80 & 6.22 \\
\hline Satisfaction & 48.28 & 7.93 \\
\hline Involvement & 44.32 & 7.28 \\
\hline Communication & 35.44 & 7.72 \\
\hline Limit Setting & 48.60 & 9.22 \\
\hline Autonomy & 51.12 & 9.67 \\
\hline Role Orientation & 51.88 & 8.90 \\
\hline
\end{tabular}




\section{Data Analysis Results}

To test the hypothesis and examine the direct impact of autism symptom severity on parent-child interaction and relationship, a multivariate regression analysis was conducted. Two separate analyses were run. The first examined the relationship between the ADOS autism symptom severity score and the DCS subscale scores for parent-child interaction. The second analysis examined the relationship between the ADOS autism symptom severity score and the PCRI subscale scores for parent-child relationship. Data analysis was conducted using the SPSS ${ }^{\circledR}$ Version 17.0 software package.

\section{Major Findings}

Initially, simple bivariate correlations between autism symptom severity, parent-child interaction subscale scores, and parent-child relationship subscale scores were computed using Pearson $r$. Based on the correlations shown in Table 4, autism symptom severity was significantly, negatively, and strongly related to the following parent-child interaction subscales: coordination $(r=-.520, p<.01)$, communication $(r=-.640, p<.01)$, emotional expression $(r=-.493$, $p<.05)$, responsivity $(r=-.465, p<.05), \operatorname{mood}(r=-.419, p<.05)$, overall interaction $(r=-.552$, $p<.01)$. Autism symptom severity was not significantly related to the parent-child interaction subscales or partner roles $(r=-.245)$, tension/relaxation $(r=-.385)$, or enjoyment $(r=-.342)$. 
Table 4

Correlation Coefficients for Symptom Severity and Parent-Child Interaction

\begin{tabular}{ll}
\hline \multicolumn{1}{c}{ Measure } & Autism Symptom Severity \\
\hline Coordination & $-.520^{* *}$ \\
Communication & $-.640^{* *}$ \\
Partner Roles & -.245 \\
Emotional Expression & $-.493^{*}$ \\
Responsivity & $-.465^{*}$ \\
Tension $/$ Relaxation & -.385 \\
Mood & $-.419^{*}$ \\
Enjoyment & -.342 \\
Overall Interaction & $-.552^{* *}$ \\
\hline Note. ${ }^{*} p<.05, * * p<.01$. & \\
\hline
\end{tabular}

Based on the correlations shown in Table 5, autism symptom severity was not significantly related to any of the parent-child relationship subscales: support $(r=.135)$, satisfaction $(r=.323)$, involvement $(r=.205)$, communication $(r=.098)$, limit setting $(r=.329)$, autonomy $(r=.195)$, or role orientation $(r=.390)$. 
Table 5

Correlation Coefficients for Symptom Severity and Parent-Child Relationships

Measure Autism Symptom Severity

\begin{tabular}{ll}
\hline Support & .135 \\
Satisfaction & .323 \\
Involvement & .205 \\
Communication & .098 \\
Limit Setting & .329 \\
Autonomy & .195 \\
Role Orientation & .390 \\
\hline Note. ${ }^{*} p<.05, * * p<.01$. & \\
\hline
\end{tabular}

Bivariate correlations between the individual subscales for each variable were also computed using Pearson's $r$. This was done in order to identify any significant relationships existing between the subscales on the various measures, and not just in relation to autism symptom severity. The correlation matrix provided in Table 6 shows the results of these correlations, indicating that numerous significant relationships exist between the subscales for the dependent variable. 
Table 6

Correlation Matrix Among Research Variables

\begin{tabular}{|c|c|c|c|c|c|c|c|c|c|c|c|c|c|c|c|c|}
\hline & ADOS & $\begin{array}{c}\text { Co- } \\
\text { ordination }\end{array}$ & $\begin{array}{c}\text { DCS } \\
\text { Comm. }\end{array}$ & $\begin{array}{c}\text { Partner } \\
\text { Roles }\end{array}$ & $\begin{array}{l}\text { Emotional } \\
\text { Expressions }\end{array}$ & Responsivity & $\begin{array}{c}\text { Tension } \\
\text { Relaxation }\end{array}$ & Mood 1 & Enjoyment & Overall & Support & Satisfaction & Involvement & $\begin{array}{l}\text { PCRI } \\
\text { Comm. }\end{array}$ & $\begin{array}{l}\text { Limit } \\
\text { Setting }\end{array}$ & Autonomy \\
\hline Co-ordination & $-.520^{* *}$ & & & & & & & & & & & & & & & \\
\hline Communication & $-.640^{* *}$ & $.889^{* *}$ & & & & & & & & & & & & & & \\
\hline Partner Roles & -.245 & $.816^{* *}$ & $.760^{* *}$ & & & & & & & & & & & & & \\
\hline $\begin{array}{l}\text { Emotional } \\
\text { Expressions }\end{array}$ & $-.493^{*}$ & $.780^{* *}$ & $.811^{* *}$ & $.737^{* *}$ & & & & & & & & & & & & \\
\hline Responsivity & $-.465^{*}$ & $.913^{* *}$ & $.881^{* *}$ & $.858^{* *}$ & $.856^{* *}$ & & & & & & & & & & & \\
\hline $\begin{array}{l}\text { Tension } \\
\text { Relaxation }\end{array}$ & -.385 & $.675^{* *}$ & $.638^{* *}$ & $.683^{* *}$ & $.857^{* *}$ & $.845^{* *}$ & & & & & & & & & & \\
\hline Mood & $-.419^{*}$ & $.720^{* *}$ & $.661^{* *}$ & $.634^{* *}$ & $.874^{* *}$ & $.796^{* *}$ & $.836^{* *}$ & & & & & & & & & \\
\hline Enjoyment & -.342 & $.766^{* *}$ & $.685^{* *}$ & $.678^{* *}$ & $.904^{* *}$ & $.853^{* *}$ & $.883^{* *}$ & $.866^{* *}$ & & & & & & & & \\
\hline Overall & $-.552^{* *}$ & $.895^{* *}$ & $.885^{* *}$ & $.819^{* *}$ & $.913^{* *}$ & $.949^{* *}$ & $.858^{* *}$ & $.843^{* *}$ & $.881^{* *}$ & & & & & & & \\
\hline Support & .135 & -.163 & -.145 & -.198 & -.211 & -.266 & $-.443^{*}$ & -.144 & -.264 & -.242 & & & & & & \\
\hline Satisfaction & .323 & -.019 & -.004 & .138 & .045 & .091 & .001 & .050 & .173 & .000 & .296 & & & & & \\
\hline Involvement & .205 & -.238 & -.274 & -.124 & -.091 & -.045 & .088 & -.011 & -.014 & -.124 & .035 & .361 & & & & \\
\hline PCRI Comm. & .098 & .021 & .049 & -.019 & -.071 & -.084 & -.180 & .133 & -.041 & -.056 & $.537^{* *}$ & .274 & .003 & & & \\
\hline Limit Setting & .329 & -.182 & -.183 & -.054 & -.251 & -.302 & $-.431^{*}$ & -.246 & -.302 & -.321 & $.655^{* *}$ & $.398^{*}$ & .003 & $.504^{*}$ & & \\
\hline Autonomy & .195 & -.236 & -.280 & -.193 & -.376 & -.393 & $-.566^{* *}$ & -.335 & -.394 & -.362 & $.607^{* *}$ & .313 & .098 & .283 & $.696^{* *}$ & \\
\hline $\begin{array}{l}\text { Role } \\
\text { Orientation }\end{array}$ & .390 & -.023 & -.196 & .032 & .061 & .040 & .170 & .210 & .246 & -.022 & .075 & $.567^{* *}$ & .246 & .126 & .105 & .162 \\
\hline
\end{tabular}

Note. ${ }^{*} p<.05, * * p<.01$ 
To further analyze the data, two separate multivariate regressions were conducted to examine the prediction of autism symptom severity (ADOS) on parent-child interaction (DCS) and parent-child relationship (PCRI). While the original power analysis specified an alpha of .05 with a large effect size, the inclusion of only 25 participants reduced the overall power of the findings. Ideally, given seven predictor variables, a sample size of 44 participants would have been utilized to achieve an alpha of .05 with a large effect size (Green, 1991). A Bonferroni adjustment was considered, given the small sample size and the number of variables being analyzed. However the stringent requirements for significance when using the Bonferroni adjustment seemed unnecessary for a study of this preliminary nature. Utilizing the Bonferroni adjustment would potentially increase the likelihood of committing a Type II error (Nakagawa, 2004). Therefore, the adjustment was not utilized and the small sample size and subsequent reduced power are recognized as a limitation of this study.

The results of the regression with ADOS predicting DCS (Co-ordination, Communication, Partner Roles, Emotional Expressions, Responsivity, Tension Relaxation, Mood, Enjoyment and Overall) were significant, $F(9,15)=3.38, p<.05$, suggesting that ADOS simultaneously predicts the DCS subscales. ADOS was a significant predictor of Co-ordination, $t$ $(24)=2.92, p<.01$, and ADOS accounted for $\left(R^{2}\right) 27.0 \%$ of the variance in Co-ordination. The results suggest that for every one unit increase in ADOS, Co-ordination will decreases by 0.49 units. ADOS was a significant predictor of Communication, $t(24)=3.99, p<.01$, and ADOS accounted for $\left(R^{2}\right) 40.9 \%$ of the variance in Communication. The results suggest that for every one unit increase in ADOS, Communication will decreases by 0.73 units.

ADOS was a significant predictor of Emotional Expression, $t(24)=2.72, p<.05$, and ADOS accounted for $\left(R^{2}\right) 24.4 \%$ of the variance in Emotional Expression. The results suggest 
that for every one unit increase in ADOS, Emotional Expressions will decreases by 0.58 units. ADOS was a significant predictor of Responsivity, $t(24)=2.59, p<.05$, and ADOS accounted for $\left(R^{2}\right) 21.6 \%$ of the variance in Responsivity. The results suggest that for every one unit increase in ADOS, Responsivity will decreases by 0.39 units. ADOS was a significant predictor of Mood, $t(24)=2.21, p<.05$, and ADOS accounted for $\left(R^{2}\right) 17.6 \%$ of the variance in Mood. The results suggest that for every one unit increase in ADOS, Mood will decreases by 0.44 units. ADOS was a significant predictor of Overall Interaction, $t(24)=3.18, p<.01$, and ADOS accounted for $\left(R^{2}\right) 30.5 \%$ of the variance in Overall Interaction. The results suggest that for every one unit increase in ADOS, Overall Interaction will decreases by 0.50 units.

ADOS was not identified as a significant predictor of Partner Roles, Tension Relaxation, or Enjoyment. Therefore, there was no predictable connection between changes in ADOS scores and changes in these parent-child interaction subscales. It is possible that parents and children experience tension and/or enjoyment within their interactions based on factors other than symptom severity. This may particularly be the case if the parent is interacting with the child around activities or items of interest, leading to a higher level of enjoyment overall in the interaction despite the presence of more severe autism symptoms. The lack of a significant relationship between three of the parent-child interaction subscale scores and autism symptom severity should, yet a strong relationship between the overall parent-child interaction score and symptom severity, seems noteworthy and in need of further study. The results of ADOS predicting DCS are presented in Table 7. 
Table 7

Multivariate Regression with ADOS predicting DCS Subscales of Co-ordination,

Communication, Partner Roles, Emotional Expression, Responsivity, Tension Relaxation, Mood, Enjoyment, and Overall Interaction

\begin{tabular}{lcccccc}
\hline Dependent Variable & $\mathrm{B}$ & $\mathrm{SE}$ & $t$ & $p$ & $\mathrm{R}^{2}$ & Power \\
\hline & & & & & \\
Co-ordination & -0.49 & 0.17 & -2.92 & .008 & .270 & 0.80 \\
Communication & -0.73 & 0.18 & -3.99 & .001 & .409 & 0.97 \\
Partner Roles & -0.18 & 0.15 & -1.21 & .237 & .060 & 0.21 \\
Emotional Expression & -0.58 & 0.21 & -2.72 & .012 & .244 & 0.74 \\
Responsivity & -0.39 & 0.15 & -2.52 & .019 & .216 & 0.68 \\
Tension Relaxation & -0.39 & 0.19 & -2.00 & .057 & .149 & 0.48 \\
Mood & -0.44 & 0.20 & -2.21 & .037 & .176 & 0.56 \\
Enjoyment & -0.34 & 0.19 & -1.75 & .094 & .117 & 0.39 \\
Overall & -0.50 & 0.16 & -3.18 & .004 & .305 & 0.86 \\
\hline
\end{tabular}

The results of the regression with ADOS predicting PCRI (Support, Satisfaction, Involvement, Communication, Limit Setting, Autonomy and Role Orientation) were not significant, $F(7,17)=0.94, p=.503$. This suggests that ADOS does not simultaneously predict the PCRI subscales. There was no predictable connection between changes in ADOS scores and changes in PCRI scores. This is notable, as it indicates that parent perception of the parent-child relationship is independent of the child's symptom severity. Parents may have a child with 
severe symptoms, yet have a high quality relationship with them. Conversely, parents may have a child with less severe symptoms yet rate the quality of their relationship as poor. It is possible that factors such as parenting style, experiences parenting other children, and parent mental/emotional state influence parent perception of the parent-child relationship; rather than the child's symptom severity. This inconsistency in the findings, parent-child relationship being unrelated to symptom severity while parent-child interaction is significantly related to symptom severity, indicates the need for further study. The results of ADOS predicting PCRI subscales are presented in Table 8 .

Table 8

Multivariate Regression with ADOS predicting PCRI Subscales of Support, Satisfaction, Involvement, Communication, Limit Setting, Autonomy, and Role Orientation

\begin{tabular}{lcccccc}
\hline Dependent Variable & $\mathrm{B}$ & $\mathrm{SE}$ & $t$ & $p$ & $\mathrm{R}^{2}$ & Power \\
\hline Support & 0.56 & 0.85 & 0.65 & .520 & .018 & 0.10 \\
Satisfaction & 1.70 & 1.04 & 1.64 & .115 & .104 & 0.35 \\
Involvement & 0.99 & 0.99 & 1.00 & .326 & .042 & 0.16 \\
Communication & 0.50 & 1.06 & 0.47 & .642 & .010 & 0.07 \\
Limit Setting & 2.01 & 1.20 & 1.67 & .109 & .108 & 0.36 \\
Autonomy & 1.25 & 1.31 & 0.95 & .350 & .038 & 0.15 \\
Role Orientation & 2.30 & 1.13 & 2.03 & .054 & .152 & 0.49 \\
\hline
\end{tabular}




\section{Summary}

Based on the findings of the multivariate regression analysis, the Null Hypothesis was accepted for parent-child relationship and rejected for parent-child interaction. Therefore, the Alternate Hypothesis was accepted for parent-child interaction and rejected for parent-child relationship. The results of the multivariate regression analysis showed significant relationships between autism symptom severity and parent-child interaction. As autism symptom severity increased, the quality of parent-child interaction decreased. However, a significant relationship between autism symptom severity and parent-child relationship was not found. Autism symptom severity did not predict any of the parent-child relationship subscales. This supports the position that autism symptom severity is related to parent-child interaction, but not to the overall parentchild relationship. These results indicate that the Alternate Hypothesis is accurate only for parent-child interaction, and the Null Hypothesis holds for parent-child relationship.

Chapter 5 will provide a brief summary of the study, and explain why and how the study was undertaken and performed. Conclusions will be drawn based on the findings, and their impact on social change will be discussed. Recommendations will be offered for future action and further research. 
Chapter 5: Discussion, Conclusion, and Recommendations

This chapter is arranged in five sections. The first section provides a brief overview of why and how the study was done, a review of the research question, and a brief summary of findings. The second section provides the interpretation of findings, which includes the conclusions that answer the research question posed for the study. Implications for social change are discussed in the third section. The fourth section makes recommendations for action, and the fifth and final section offers recommendations for further study.

\section{Study Overview}

The purpose of this quantitative study was to investigate the impact of autism symptom severity on parent-child interaction and relationships. Specifically, I attempted to answer the research question: Does autism symptom severity as measured by the Autism Diagnostic Observation Schedule (ADOS) predict parent-child relationship as measured by the Parent Child Relationship Inventory (PCRI), and parent-child interaction as measured by the Dyadic Coding Scale (DCS)? This study was also intended to address the problem of lack of research in the area of bidirectional relationships between children with autism and their parents.

The reason for undertaking this study and its intrinsic importance was the fact that, at this time, little research has been done to identify specific relational elements requiring consideration in autism symptom reduction efforts. The number of children diagnosed with autism continues to dramatically rise (CDC, 2007); yet a clear picture of how to improve development and outcomes in this population has yet to be developed (Bodfish, 2004). It is evident from the literature concerning the bidirectional model of parent-child relationships that parents and children influence the development of each other and, consequently, themselves in both positive and negative ways (DeMol \& Buysse, 2008). However, research has not identified specific 
elements of moment-to-moment interactions and aspects of overall parent-child relationships that are impacted by symptoms of autism. It was clear, therefore, that more research attention needed to be directed toward this area.

\section{Interpretation of the Findings}

Preliminary analysis revealed that the alternate hypothesis, stating that a significant statistical relationship exists between autism symptom severity and parent-child interaction, had to be accepted for parent-child interaction. The results showed that autism symptom severity was highly correlated with parent-child interaction. The results also revealed that six specific parent-child interaction subscale scores had a significant inverse relationship to autism symptom severity scores. As autism severity scores increased, the scores on those subscales of parentchild interaction decreased. Three of the subscales were not significantly related to autism symptom severity scores. Increased symptom severity had an overall negative impact on parentchild interaction.

Preliminary analysis also revealed that the null hypothesis, stating that a significant statistical relationship does not exist between autism symptom severity and parent-child relationship, had to be accepted for parent-child relationships. The results showed that autism symptom severity was not correlated with parent-child relationship. A statistically significant relationship between autism symptom severity and parent-child relationship was not evident for any of the seven parent-child relationship subscales. Parent perceptions of their relationships with their children, therefore, do not appear to be influenced by the severity of autism symptoms. These findings support earlier results reported by Hobson and colleagues (2008), in which disruptions in parent-child interaction were common while aspects of the overall parent-child relationship were unaffected. 
The bidirectional model of parent-child relations (Bell, 1968) forms the theoretical base of this study and lends some support for the apparent discrepancy between interactions and relationships. This model indicates that the overall relationship is not merely the sum of all interactions. Rather, moment-to-moment interactions are one relational aspect to consider when looking at the overarching parent-child relationship. Relationships are identified primarily by the level of endurance and the strength of connectedness between the individuals involved (Reis et al., 2000). It is not unreasonable, then, for the results of this study to demonstrate that autism symptom severity impacts elements of interaction but not the overall relationship between parent and child. However, these results contradict previous findings showing that symptom severity does impact parent-child relationships (Hoffman et al., 2009). Further research is clearly needed to more fully understand the connections between parent-child interaction and relationships in this population.

The DCS domains found to have a significant inverse relationship were coordination, communication, emotional expression, responsivity, mood, and overall quality. Low scores on coordination indicated that the interaction was unproductive and involved friction between parties, while high scores indicated harmony and balance in the interaction. Low scores on communication indicated the presence of ignoring behaviors, withdrawal, incongruent utterances, and awkward silences, with high scores given for congruent, reflective, and clear communication. Low scores on emotional expression indicated intense and constricted emotional exchanges, with high scores indicating a range of emotions that were encouraged and freely expressed. Low scores on responsivity indicated under involvement, distraction, rejection, and indifference, while high scores indicated evidence of perspective taking, focused attention, and empathy. Low scores on mood indicated a pervasive negative mood coupled with 
depression, anxiety, and/or anger, with high scores indicating a predominantly positive mood and encouraging presence. Low scores on overall quality indicated a general sense of indifference, lack of pleasure, and conflict, with high scores indicating genuine interest, enjoyment, and harmonious interaction. It is evident that all six of these subscales can be predicted by child autism symptom severity.

The DCS domains not found to have a significant relationship with autism symptom severity included partner roles, tension/relaxation, and enjoyment. Partner roles identify the degree to which children and parents retain their appropriate roles concerning control of interaction, and the manners with which they seek to maintain control. Tension/relaxation measures the amount of anxiety and tension evident in the interaction, including nervous habits and degree of openness. Enjoyment identifies the amount of pleasure and warmth exhibited during the interaction, including approval and engagement. The findings suggest that partner roles, tension/relaxation, and enjoyment cannot be predicted by child autism symptom severity. Mean scores for these domains fall in the same range as the mean scores for all other domains. Therefore, these components of interaction appear to be scored as higher or lower independent of the severity of the child's autism symptoms.

Examination of the PCRI data indicated that none of the domains were predicted by autism symptom severity. Scores were higher or lower independent of the child's symptom severity level in all domains, including support, satisfaction, involvement, communication, limit setting, autonomy, and role orientation. Support measured the amount of emotional and social support received by parents. Satisfaction measured the amount of pleasure and fulfillment derived from parenting. Involvement identified the parent's level of knowledge of and interaction with his/her child. Communication measured parent perception regarding 
communication effectiveness with the child. Limit setting indicated the parent's discipline experiences with the child. Autonomy identified the parent's ability to promote child independence. Role orientation examined parent attitudes regarding gender roles in parenting. Findings from this study indicate that parent perception of the relationship with their child is positive overall, regardless of the child's symptom severity. This supports previous research showing that children with autism have levels of attachment with their parents that mirror the population of typically developing children (Al-Yagon \& Mikulincer, 2004). It is not entirely surprising, therefore, that the overall relationship does not seem to be impacted by symptom severity specifically. However, there is evidence in the research literature that contradicts these findings, and indicates that symptom severity does impact parent-child relationships in negative ways (Hoffman et al., 2009; VanHooste \& Maes, 2003).

Mean scores for the various domains of the PCRI indicated that parents displayed attitudes congruent with good parenting for all but the domain of communication. The mean score in the communication domain indicated that parents perceived problems in this area regardless of their child's autism symptom severity level. This revealed that parent perception of communication effectiveness appears to be negatively impacted by autism, regardless of the severity of the child's symptoms. Autism by definition involves communication deficits regardless of symptom severity. Therefore, it makes sense that parents would struggle to communicate with their autistic children regardless of the children's levels of communication abilities.

Analysis of relationships between DCS and PCRI domains provided evidence of a number of significant relationships between research variables. On the DCS, all domains were found to have statistically significant positive relationships with each other. That is, as one 
domain score increased, so did all others; and as one domain score decreased, so did all others. This provides evidence of the inherent intertwining of these aspects of interaction. It also suggests that positive or negative impact on one area of interaction could produce corresponding positive or negative impact on the remaining areas of interaction.

Examination of statistically significant relationships among PCRI and DCS data revealed various findings. The only DCS domain found to be significantly related to PCRI domains was the tension/relaxation domain. An inverse relationship was found between tension/relaxation scores on the DCS and limit setting and autonomy scores on the PCRI. Higher scores on the tension/relaxation domain indicated less anxiety and more openness, but were related to lower scores on the limit setting domain, indicating less perceived competence with disciplining the child. It may be that parents reduce their anxiety and that of their children by refraining from limit setting and, therefore, do not perceive themselves to be very effective with discipline, as has been discussed by Darling and Steinberg (1993). Higher scores on tension/relaxation also were related to lower scores on autonomy, indicating a perception of less parental ability to promote the child's independence. This finding seems unusual, as it stands to reason that parents who promote dependence in their child and fear allowing them to experience failure or disappointment would be quite anxious about their encounters together. However, it may be the case that the parent does everything for the child to avoid failure or disappointment, which leads to a relaxed and open tone during interactions. More research specific to these domains is necessary in order to understand the true nature of these relationships.

Significant relationships among PCRI domains were also found. The domain of support had a significant positive relationship to the domains of communication, limit setting, and autonomy. This indicated that as the amount of perceived emotional and social support for 
parents increased, so did the perceived competence with communication, limit setting, and autonomy. Likewise, as the amount of perceived support decreased, so too did the perception of competence in these other areas. Therefore, it appears that parent perception of emotional and social support is important for several aspects of the overall relationship with the child. This supports previous research findings regarding the impact of parental education and support on overall parenting ability and child outcomes (Levy, Kim, \& Olive, 2006). Parents who feel more supported are better able to provide effective discipline to their children, as well as communicate more effectively and promote independence. Limit setting and autonomy were also significantly related, with the scores rising and falling in conjunction with each other. Parents who perceived themselves to be more effective limit setters with their children also felt more competent with promoting independence in their child. Those parents who felt less able to set limits also indicated a tendency to promote dependence on the part of their child. Previous research results have indicated a similar relationship between limit setting and autonomy-focused parenting styles (Whittingham, Sofronoff, Sheffield, \& Sanders, 2009).

The communication domain on the PCRI was also significantly related to the limit setting domain. As parent perception of communication effectiveness increased, so did perceptions of limit setting. Likewise, as communication effectiveness decreased, so did limit setting. This indicated that perceptions of communication effectiveness and limit setting are interrelated. The final significant relationships found in the PCRI domains were between satisfaction, limit setting, and role orientation. These findings indicated that overall parenting satisfaction rises or falls along with both the ability to set effective limits with the child as well as the perception of gender roles in parenting. It may be that parents who perceive that their current parenting role situation is aligned with their beliefs about gender roles feel a greater sense of parenting 
satisfaction than those for whom they are not aligned. This also indicates that the ability to set effective limits with the child is important for overall parenting satisfaction.

\section{Implications for Social Change}

The large number of children currently being diagnosed with autism presents a need for greater understanding of how autism symptom severity impacts interaction and relationships in this population. While previous research has identified some methods for improving functioning in diagnosed individuals, to date there is a lack of clarity around the types of interventions that result in improved long term functioning and greater independence (Bodfish, 2007). Autism has been shown to impact negatively many aspects of family life and individual functioning (Baker, Blacher, \& Olsson, 2005; Bernard et al., 2001; Eaves \& Ho, 2008; Pakenham, Samios, \& Sofronoff, 2005). In addition, society now bears an increased burden of caring for affected individuals over the long term, resulting in increased costs and pressures on state and national social service agencies (Ganz, 2007).

There are a number of implications of the current research findings for the development and refining of treatment approaches. The strong inverse relationship between symptom severity and parent interaction indicates that the areas of interaction measured by the DCS may be core deficits in children with autism that require specific remedial treatment efforts. If these are, in fact, core symptoms, it is possible that interventions targeting these specific areas of interaction could improve symptom severity in affected children. Treatment focused on improving parentchild interaction in the areas of coordination, communication, emotional expression, responsivity, and mood may positively impact the overall quality of interaction and, thus, the severity of autism symptoms. This makes logical sense given the research on the bidirectional nature of parent-child relationships, which has shown that parents and children impact one 
another in a cyclical way (Kuczynski, Loulis, \& Koguchi, 2003). If one partner makes changes in the system, it automatically has an impact on the other and creates change in them as well. Therefore, it is possible that teaching parents how to alter their behaviors in these specific areas of interaction would have a positive impact on the child's symptom development and expression. Treatment development, then, should explore ways in which behaviors in these specific areas can be altered to improve child functioning, thereby reducing overall symptom severity.

The results of this study also make it clear that communication between parents and children is negatively impacted regardless of the child's symptom severity. Previous studies have shown a connection between increased child communication and more positive parent-child interaction (Kasari, Sigman, Mundy, \& Yirmiya, 1988), but results from this study indicate that parents perceive significant difficulties communicating with their child regardless of the child's level of verbal communication. Therefore, treatment should focus on improving parent communication effectiveness regardless of the severity of the child's autism. Aspects such as limit setting, developing autonomy, and parent support systems also require consideration in planning treatment programs regardless of the child's level of functioning. Previous research has demonstrated the importance of parent perception of support for maximizing parent effectiveness in positively impacting the child's overall development (VanHooste \& Maes, 2003), and the results of this study support those earlier findings..

Findings from this study also convey the usefulness of utilizing parent-child interaction as a measure of symptom change over time and/or as a result of intervention. Given the strong inverse relationship between DCS and ADOS scores, the DCS could be appropriately used over time with children and parents as a measure of symptom progression. Specifically, interventions designed to target autism symptom severity should show improvement in DCS scores over time 
if the actual core symptoms of the autism itself are being positively impacted. The issue of how best to measure progress in this population has been raised previously, with the general consensus being that tools often used to measure progress do not necessarily measure improvement in the symptom areas specific to autism (Rogers \& Vismara, 2008). Results from this study show that the DCS may be an appropriate tool to measure autism symptom change as treatment is applied over time.

On a family-oriented level, the results of this study provide insight into parent perceptions and experiences, both moment-to-moment and overall, with their autistic children. This information is valuable in the development of interventions that best support the needs of parents, and provide them tangible avenues for improving their interactions and overall relationships with their children. This has the potential to improve family functioning as a whole through reducing stress in the family system, and promoting greater family stability. Previous research has identified the importance of helping parents manage the increased stress levels associated with parenting a child with autism (Warfield, 2005), but this study's results provide some specific target areas for supporting parents in this way. In addition, research has demonstrated the benefits of involving parents in the treatment process ( Howlin, 2000). This study provides evidence of specific areas in which parents can be instructed to make shifts that may positively impact their interactions with the child.

This research also holds the potential for positive change for individuals diagnosed with autism. Understanding the areas of parent-child interaction that are impacted by autism can pave the way for parents to improve specific aspects of their interactions that promote more positive experiences for the child. Practitioners can use the DCS to identify areas of parent-child interaction that are problematic for specific parent-child pairs. This information can then be used 
to assist parents in modifying their interactions with the child. Research on the bidirectional nature of parent-child interactions has shown that child development can be impacted in a positive manner as a result of parents altering specific interactive behaviors (Arnold et al., 1993; Hoagwood, Burns, Kiser, Ringeisen, \& Schoenwald, 2001). Results of this study, then, hold the promise of improving the development of children with autism via changes parents make in their interactions with the child. This is very exciting to consider in the context of treatment planning which may provide better long-term outcomes for these individuals.

\section{Recommendations for Action}

Based on the findings of this study, it is recommended that autism intervention programs measure parent-child interaction at the start of treatment and over the course of treatment to identify areas of symptom improvement. Specifically, it is recommended that the DCS be used in evaluation and treatment planning to inform intervention efforts for both parent and child. Measuring parent-child interaction via the DCS would illuminate specific areas of breakdown in their encounters with one another, thus providing specific avenues for treatment application.

Findings of this study also demonstrate the need to address parent-child communication patterns in treatment, regardless of symptom severity. Given that parents perceive that they are ineffective communicators with their child, it is important to provide them with specific strategies to foster more effective communication. The communication domain of the PCRI could then be used to evaluate the effectiveness of such communication training for parents, in that they should indicate higher perceived communication effectiveness following education and training.

The results of this study may be disseminated to diagnostic and treatment specialists in the field via publication. Awareness of these results could spur the development of additional 
research studies investigating other aspects of parent-child interaction and relationships. The usefulness of targeting these specific areas of interaction via treatment protocols would also be valuable to explore. In addition, treatment professionals in the field may also be interested in knowing about the relationship between autism symptom severity and DCS interaction scores in order to utilize the DCS as a measure of symptom progression resulting from treatment.

Professionals involved in ongoing research and development of the ADOS can also benefit from these findings, as this is one of the first research studies to use the new calibrated severity metric for scoring.

\section{Recommendations for Further Research}

These research findings demonstrated that child autism symptom severity is a strong predictor of parent-child interaction. Future research should investigate whether this is unique to autism, or if there are other disorders that impact parent-child interaction in similar ways. This would help answer the question of whether or not the DCS identifies interaction patterns related to core symptoms of autism specifically. Therefore, it would be valuable to conduct this study with a comparison group of children without diagnoses of autism in order to identify similar or contrasting patterns across both groups of children and parents.

Another recommendation is to replicate this study using a larger and more representative population of parents and children. A larger sample would allow for more balanced representation of child and parent genders and ethnicities. In addition, larger sample size would provide greater power when analyzing results. Generalizability would also be enhanced if the findings were replicated across a larger group.

Conducting a qualitative study of parent perceptions of the relationships they have with their children would also be beneficial. Specifically, it would be interesting to explore factors 
such as resiliency and bonding that allow parents to feel positive about their relationships with these children despite them having a condition that inherently impacts their ability to communicate and relate with others. A qualitative study may illuminate specific factors involved more effectively than using quantitative measurement tools.

Another avenue of research to explore based on these findings would be in the area of treatment outcomes. Studies could be performed to identify whether DCS scores changed as a result of treatment, thus indicating improvements in parent-child interactions. It would also be valuable to conduct a study of treatment methods aimed at improving the specific aspects of parent-child interaction measured on the DCS. The DCS and ADOS could be utilized as outcome measures to identify whether autism symptomology and/or parent-child interaction changed as a result of applying these treatment methods.

A final recommendation is to explore any methods that can support parent communication efforts with their autistic children. It is critical to examine this aspect of the parent-child relationship, and provide parents with specific education and strategies to support communication with their children. The communication domain of the PCRI could be used as an outcome measure to determine the efficacy of these methods in improving parent perception of their communication effectiveness.

\section{Summary}

This study focused on a sample $(N=25)$ of children diagnosed with autism and their primary parents. The research design required a combination of survey data and coded observations related to parent-child interaction and relationships. The results of multivariate regression analysis revealed a significant relationship between autism symptom severity and parent-child interaction. A significant relationship between autism symptom severity and parent- 
child relationship was not found. These results show the critical importance of identifying patterns of parent-child interaction that may impact child functioning in positive or negative ways. In addition, attention must be paid to the impact autism has on parent child interaction and relationships regardless of the child's symptom levels, specifically in the area of parent communication effectiveness. Focusing on the ways in which parents and children interact with one another on a moment-to-moment basis can provide an appropriate starting point for intervention and improved treatment outcomes. It is hoped that this research will promote further investigation of methods for altering parent-child interaction in order to support the development and functioning of children affected by the disorder so that they may attain quality of life now and for the future. 


\section{References}

Aldred, C., Green, J., \& Adams, C. (2004). A new social communication intervention for children with autism: Pilot randomized controlled treatment study suggesting effectiveness. Journal of Child Psychology and Psychiatry, 45(8), 1420-1430.

Al-Yagon, M. \& Mikulincer, M. (2004). Socioemotional and academic adjustment among children with learning disorders: The mediational role of attachment-based factors. The Journal of Special Education, 38, 111-123.

American Psychiatric Association. (2000). Diagnostic and statistical manual of mental disorders: DSM-IV-TR. Washington, DC: Author.

Arnold, D.S., O’Leary, S.G., Wolff, L.S., \& Acker, M.M. (1993). The Parenting Scale: A measure of dysfunctional parenting in discipline situations. Psychological Assessment, 5(2), 137-144.

Babbie, E. (1998). The practice of social research. $\left(8^{\text {th }}\right.$ ed.). Belmont, CA: Wadsworth Publishing Company.

Baird, G., Simonoff, E., Pickles, A., Chandler, S., Loucas, T., Meldrum, D., et al. (2006). Prevalence of disorders of the autism spectrum in a population cohort of children in South Thames: the Special Needs and Autism Project (SNAP). Lancet, 368, 210-215.

Bakeman, R. \& Adamson, L.B. (1984). Coordinating attention to people and objects in mother-infant and peer-infant interaction. Child Development, 55(4), 1278-1289.

Baker, B.L., Blacher, J., \& Olsson, M.B. (2005). Preschool children with and without developmental delay: Behavior problems, parents' optimism and well-being. Journal of Intellectual Disability Research, 49, 575-590. 
Baumrind, D. (1966). Effects of authoritative parental control on child behavior. Child Development, 37(4), 887-907.

Beals, K.P. (2003). The ethics of autism: What's wrong with the dominant paradigms and how to fix them. Mental Retardation and Developmental Disabilities, 9, 32-39.

Bell, R.Q. (1968). A reinterpretation of the direction of effects in studies of socialization. Psychological Review, 75(2), 81-95.

Bellini, S., Peters, J., Benner, L., \& Hopf, A. (2007). A meta-analysis of school-based social skills interventions for children with autism spectrum disorders. Journal of Remedial and Special Education, 28(3), 153-162.

Belsky, J., Friedman, S.L., \& Hsieh, K.H. (2001). Testing a core emotion-regulation prediction: Does early attentional persistence moderate the effect of infant negative emotionality on later development? Child Development, 72, 123-133.

Bernard, J., Harvey, V., Potter, D., \& Prior, A. (2001). Ignored or ineligible? The reality for adults with autism spectrum disorders. London: The National Autistic Society. Bodfish, J.W. (2004). Treating the core features of autism: Are we there yet? Mental Retardation and Developmental Disabilities, 10, 318-326.

Brown, J. \& Whiten, A. (2000). Imitation, theory of mind and related activities in autism: An observational study of spontaneous behavior in everyday contexts. Autism, 4, 185-204.

Bruinsma, Y., Koegel, R.L., \& Keogel, L.K. (2004). Joint attention and children with autism: A review of the literature. Mental Retardation and Developmental Disabilities, 10, 169-175.

Buchner, A., Erdfelder, E., \& Faul, F. (1997). How to Use G*Power [WWW document]. 


\section{URL:}

http://www.psycho.uniduesseldorf.de/aap/projects/gpower/how to use_gpower.html.

Cashin, A. (2004). Painting the vortex: The existential structure of the experience of parenting a child with autism. International Forum for Psychoanalysis, 13, 164174.

Centers for Disease Control and Prevention (CDC). (2007). Prevalence of-Autism Spectrum Disorders --- Autism and Developmental Disabilities Monitoring Network, Six Sites, United States, 2000. MMWR SS 2007; 56(No.SS-1).

Charman, T. (2005). Why do individuals with autism lack the motivation or capacity to share intentions? Behavioral and Brain Sciences, 28(5), 695-696.

Charman, T., Swettenham, J., Baron-Cohen, S., Cox, A., Baird, G., \& Drew, A. (1997). Infants with autism: An investigation of empathy, pretend play, joint attention, and imitation. Developmental Psychology, 33(5), 781-789.

Child and Adolescent Health Measurement Initiative. 2007 National Survey of Children's Health, Data Resource Center for Child and Adolescent Health website. Retrieved August 13, 2009 from: www.nschdata.org.

Cimera, R.E. \& Cowan, R.J. (2009). The costs of services and employment outcomes achieved by adults with autism in the US. Autism: The International Journal of Research \& Practice, 13(3), 285-302.

Coffman, J.K., Guerin, D.W., \& Gottfried, A.W. (2006). Reliability and validity of the parent-child relationship inventory (PCRI): Evidence from a longitudinal crossinformant investigation. Psychological Assessment, 18(2), 209-214.

Collins, W.A., Maccoby, E.E., Steinberg, L., Hetherington, E.M., \& Bornstein, M.H. 
(2000). Contemporary research on parenting: The case for nature and nurture. American Psychologist, 55(2), 218-232.

Constantino, J.N. \& Gruber, C.P. (2005). Social Responsiveness Scale Manual. Los Angeles, CA: Western Psychological Services.

Constantino, J.N., Przybeck, T., Friesen, D., \& Todd, R.D. (2000). Reciprocal social behavior in children with and without pervasive developmental disorders. Journal of Developmental and Behavioral Pediatrics, 21, 2-11.

Cummings, E.M., Davies, P.T., \& Campbell, S.B. (2000). Developmental psychopathology and family process: Theory, research, and clinical implications. New York: Guilford Press.

Darling, N. \& Steinberg, L. (1993). Parenting style as context: An integrative model. Psychological Bulletin, 113(3), 487-496.

Davila, J. \& Levy, K.N. (2006). Introduction to the special section on attachment theory and psychotherapy. Journal of Consulting and Clinical Psychology, 74(6), 989993.

DeMol J., \& Buysse, A. (2008). The phenomenology of children's influence on parents. Journal of Family Therapy, 30, 163-193.

DeMol, J. \& Buysse, A. (2008). Understandings of children's influence in parent child relationships: A Q-methodological study. Journal of Social and Personal Relationships, 25, 359-379.

Eaves, L.C. \& Ho, H.H. (2008). Young adult outcome of autism spectrum disorders. Journal of Autism \& Developmental Disorders, 38(4), 739-747.

Estes, A., Munson, J., Dawson, G., Koehler, E., Zhou, X.H., \& Abbott, R. (2009). 
Parenting stress and psychological functioning among mothers of preschool children with autism and developmental delay. Autism, 13(4), 375-387.

Field, T. (1998). Maternal depression effects on infants and early intervention. Preventative Medicine, 27, 200-203.

Fogel, A. (1993). Developing through relationships. Chicago: University of Chicago Press.

Fogel, A. (2009). What is a transaction. In A.J. Sameroff (Ed.). The transactional model of development: How children and contexts shape each other. Washington, D.C.: American Psychological Association.

Freudenheim, M. (2004). Battling insurers over autism treatment. [Electronic version]. The New York Times, December 21, 2004.

Ganz, M. L. (2007). The lifetime distribution of the incremental societal costs of autism. Archives of Pediatric and Adolescnet Medicine, 161: 343-349.

Gerard, A.B. (1994). Parent-Child Relationship Inventory (PCRI) Manual. Los Angeles: WPS.

Gernsbacher, M.A. (2006). Toward a behavior of reciprocity. Journal of Developmental Processes, 1, 139-152.

Gotham, K., Pickles, A., \& Lord, C. (2009). Standardizing ADOS scores for a measure of severity in autism spectrum disorders. Journal of Autism and Developmental Disorders, 39, 693-705.

Gotham, K., Risi, S., Dawson, G., Tager-Flusberg, H., Joseph, R., Carter, A., et al. (2008). A replication of the Autism Diagnostic Observation Schedule (ADOS) revised algorithms. Journal of the American Academy of Child and Adolescent 
Psychiatry, 47(6), 642-651.

Gotham, K., Risi, S., Pickles, A., \& Lord, C. (2007). The Autism Diagnostic Observation Schedule: Revised algorithms for improved diagnostic validity. Journal of Autism and Developmental Disorders, 37, 613-627.

Gutstein, S.E. \& Whitney, T. (2002). Asperger syndrome and the development of social competence. Focus on Autism and Other Developmental Disabilities, 17, 161172.

Harach, L.D. \& Kuczynski, L.J. (2005). Construction and maintenance of parent-child relationships: Bidireactional contributions from the perspective of parents. Infant and Child Development, 14, 327-343.

Hastings, R.P. (2002). Parental stress and behaviour problems of children with developmental disability. Journal of Intellectual \& Developmental Disability, 27(3), 149-160.

Hedenbro, M. \& Tjus, T. (2007). A case study of parent child interactions of a child with autistic spectrum disorder (3-48 months) and comparison with typicallydeveloping peers. Child Language Teaching and Therapy, 23, 201-222.

Higgins, D.J., Bailey, S.R., \& Pearce, J.C. (2005). Factors associated with functioning style and coping strategies of families with a child with an autism spectrum disorder. Autism, 9(2), 125-137.

Hoagwood, K., Burns, B.J., Kiser, L., Ringeisen, H., Schoenwald, S.K. (2001). Evidencebased practice in child and adolescent mental health services. Psychiatric Services, 52(9), 1179-1189. 
Hobson, J. A., Hobson, R. P., Gutstein, S., Ballarani, A., \& Bargiota, K. (2008, May). Caregiver-child relatedness in autism: What changes with intervention? Poster presented at the International Meeting for Autism Research, May 15 - 17, London, UK.

Hobson, P. (2004). The cradle of thought: Exploring the origins of thinking. New York: Oxford University Press.

Hoffman, C.D., Sweeney, D.P., Hodge, D., Lopez-Wagner, M.C., \& Looney, L. (2009). Parenting stress and closeness: Mothers of typically developing children and mothers of children with autism. Focus on Autism and Other Developmental Disabilities, 24(3), 178-187.

Howell, D. C. (1992). Statistical methods for psychology ( $3^{\text {rd }}$ ed.). Boston, MA: Kent Publishing Company.

Howlin, P. (1998). Practitioner review: Psychological and educational treatments for autism. Journal of Child Psychology and Psychiatry, 39(3), 307-322.

Howlin, P. (2000). Autism and intellectual disability: Diagnostic and treatment issues. Journal of the Royal Society of Medicine, 93, 351-355.

Howlin, P., Magiati, I., \& Charman, T. (2009). Systematic review of early intensive behavioral interventions for children with autism. American Journal of Intellectual and Developmental Disabilities, 114(1), 23-41.

Humber, N. \& Moss, E. (2005). The relationship of preschool and early school age attachment to mother-child interaction. American Journal of Orthopsychiatry, 75(1), 128-141.

Jocelyn, L.J., Casiro, O.G., Beattie, D., Bow, J., \& Kneisz, J. (1998). Treatment of children with autism: A randomized controlled trial to evaluate a caregiver-based 
intervention program in community day-care centers. Developmental and Behavioral Pediatrics, 19(5), 326-334.

Jones, E.A., Carr, E.G., \& Feeley, K.M. (2006). Multiple effects of joint attention intervention for children with autism. Behavior Modification, 30(6), 782-834.

Jordan, R. (2003). Social play and autistic spectrum disorders: A perspective on theory, implications, and educational approaches. Autism, 7, 347-360.

Kasari, C., Sigman, M., Mundy, P., \& Yirmiya, N. (1988). Caregiver interactions with autistic children. Journal of Abnormal Child Psychology, 16(1), 45-56.

Koren-Karie, N., Oppenheim, D., Dolev, S., \& Yirmiya, N (2009). Mother of securely attached children with autism spectrum disorder are more sensitive than mothers of insecurely attached children. Journal of Child Psychology \& Psychiatry, 50(5), 643-650.

Kuczynski, L. (2003). Beyond bidirectionality: Bilateral conceptual frameworks for understanding dynamics of parent-child relations. In L. Kuczynski (Ed.), Handbook of dynamics in parent-child relations (pp. 3-24). Thousand Oaks, CA: SAGE.

Kuczynski, L., Loulis, S., \& Koguchi, Y. (2003). Reconstructing common sense: Metaphors of bidirectionality in parent-child relations. In L. Kuczynski (Ed.), Handbook of dynamics in parent-child relations (pp. 421-437). Thousand Oaks, CA: SAGE.

Laursen, B. \& Bukowski, W.M. (1997). A developmental guide to the organization of close relationships. International Journal of Behavioral Development, 21(4), 747770. 
Lawson, K.R. \& Ruff, H.A. (2004). Early attention and negative emotionality predict later cognitive and behavioural function. International Journal of Behavioral Development, 28, 157-165.

Lemanek, K.L., Stone, W.L., \& Fishel, P.T. (1993). Parent-child interactions in handicapped preschoolers: The relation between parent behaviors and compliance. Journal of Clinical Child Psychology, 22(1), 68-77.

Levy, S., Kim, A.H., \& Olive, M.L. (2006). Interventions for young children with autism: A synthesis of the literature. Focus on autism and other developmental disabilities, 21(1), 55-61.

Lewis, V. \& Boucher, J. (1988). Spontaneous, instructed, and elicited play in relatively able autistic children. British Journal of Developmental Psychology, 6, 325-339.

Liebal, K., Colombi, C., Rogers, S., Warneken, F., \& Tomasello, M. (2008). Helping ad cooperation in children with autism. Journal of Autism and Developmental Disorders, 38, 224-238.

Lord, C., Rutter, M., DiLavore, P., \& Rissi, S. (2002). Autism Diagnostic Observation Schedule Manual. Los Angeles, CA: Western Psychological Services.

Loulis, S. \& Kuczynski, L. (1997). Beyond one hand clapping: Seeing bidirectionality in parent-child relations. Journal of Social and Personal Relationships, 14(4), 441461.

Maccoby, E.E. (1992). The role of parents in the socialization of children: An historical overview. Developmental Psychology, 6, 1006-1017.

Maccoby, E.E. and Martin, JA. (1983). Socialization in the context of the family: Parentchild interaction. In: P. Mussen and E.M. Hetherington (Eds.). Handbook of child 
psychology,

volume IV: Socialization, personality, and social development (pp. 1-101). New York: Wiley.

Mahoney, G. \& Perales, F. (2003). Using relationship-focused intervention to enhance the social emotional functioning of young children with autism spectrum disorders. Topics in early Childhood Special Education, 23(2), 74-86.

Markus, J., Mundy, P., Morales, M., Delgado, C.E.F., \& Yale, M. (2000). Individual differences in infant skills as predictors of child-caregiver joint attention and language. Social Development, 9, 302-315.

Mayes, S.D. \& Calhoun, S.L. (2001). Non-significance of early speech delay in children with autism and normal intelligence and implications for DSM-IV Asperger's disorder. Autism, 5(1), 81-94.

Meyer, E.C., Coll, C.T., Lester, B.M., Boukydis, C.F., McDonough, S.M., \& Oh, W. (1994). Family-based intervention improves maternal psychological wellbeing and feeding interaction of preterm infants. Pediatrics, 93, 241-246.

Morgan, G.A., Leech, N. L., Gloekner, G. W. \& Barrett, K. C. (2007). SPSS for introductory statistics: Use and interpretation ( $3^{\text {rd }}$ ed.). Mahwah, NJ: Lawrence Erlbaum Associates, Publishers.

Mundy, P., Kasari, C., \& Sigman, M. (1992). Nonverbal communication, affective sharing, and intersubjectivity. Infant Behavior and Development, 15, 377-318.

Mundy, P. \& Crowson, M. (1997). Joint attention and early social communication: Implications for research on intervention with autism. Journal of Autism and Developmental Disorders, 27(6), 653-676. 
Mundy, P. \& Willoughby, J. (1998). In: Wethervy A.M., Warren S.F., Reichle, J. (Eds.). Transitions in prelinguistic communications (pp. 111-134). Baltimore, MD: Brookes.

Mundy, P., Sigman, M., Ungerer, J., \& Sherman, T. (1987). Nonverbal communication and play correlates of language development in autistic children. Journal of Autism and Developmental Disorders, 17, 349-364.

Müller, R.A. (2007). The study of autism as a distributed disorder. Mental Retardation \& Developmental Disabilities Research Reviews, 13(1), 85-95.

Nakagawa, S. (2004). A farewell to Bonferroni: The problems of low statistical power and publication bias. Behavioral Ecology, 15(6), 1044-1045.

Ozonoff, S. \& Cathcart, K. (1998). Effectiveness of a home program intervention for young children with autism. Journal of Autism and Developmental Disorders, $28(1), 25-32$.

Pakenham, K.I., Samios, C., \& Sofronoff, K. (2005). Adjustment in mothers of children with Asperger syndrome. Autism, 9, 191-212.

Panksepp, J. (1994). Emotional development yields lots of "stuff"...especially mind "stuff" that emerges from brain "stuff." In P.Ekman \& R.J. Davidson (Eds.). The nature of emotion: Fundamental questions (pp. 367-372). New York: Oxford University Press.

Reis, H.T., Collins, W.A., \& Berscheid, E. (2000). The relationship context of human behavior and development. Psychological Bulletin, 126(6), 844-872.

Reissland, N. \& Stephenson, T. (1998). Turn-taking in early vocal interaction: A comparison of premature and term infants' vocalization with their mothers. Child Care, Health, and Development, 25(6), 447-456. 
Richer, J. (2001). The insufficient integration of self and other in autism: Evolutionary and developmental perspectives. In J. Richers \& S. Coates (Eds.), Autism-the search for coherence (pp. 36-52). London: Jessica Kingsley Publishers.

Rogers, S.J. \& Vismara, L.A. (2008). Evidence-based comprehensive treatments for early autism. Journal of Clinical Child \& Adolescent Psychology, 37(1), 8-38.

Ross, H.S. \& Lollis, S.P. (1987). Communication within infant social games. Developmental Psychology, 23(2), 241-248.

Ruble, L., McDuffie, A., King, A.S., \& Lorenz, D. (2008). Caregiver responsiveness and social interaction behaviors of young children with autism. Topics in Early Childhood Special Education, 28, 158-170.

Salerni, N., Suttora, C., \& D’Odorico, L. (2007). A comparison of characteristics of early communication exchanges in mother-preterm and mother-full-term infant dyads. First Language, 27, 329-346.

Sameroff, A.J. (2009). The transactional model. In A.J. Sameroff (Ed.). The transactional model of development: How children and contexts shape each other. Washington, D.C.: American Psychological Association.

Sameroff, A.J. \& Chandler, M.J. (1975). Reproductive risk and the continuum of caretaker casualty. In F.D. Horowitz (Ed.). Review of child development research (Vol. 4). Chicago: University of Chicago Press.

Scarr, S. \& McCartney, K. (1983). How people make their own environments: A theory of genotype-environment effects. Child Development, 54, 424-435.

Schertz, H.H. \& Odom, S.L. (2007). Promoting joint attention in toddlers with autism: A parent-mediated developmental model. Journal of Autism and Developmental 
Disorders, 37,1562-1575.

Sears, R.R., Maccoby, E.E., \& Levin, J. Patterns of child rearing. Evanston, Illinois: Row and Peterson, 1957.

Sherratt, D. \& Donald, G. (2004). Connectedness: Developing a shared construction of affect and cognition in children with autism. British Journal of Special Education, $31(1), 10-15$.

Sigman, M. \& Ruskin, E. (1999). Continuity and change in social competence. New York: Wiley-Blackwell.

Sigman, M., Spence, S.J., \& Wang, T. (2006). Autism from developmental and neuropsychological perspectives. Annual Review of Clinical Psychology, 2, 327355.

Siller, M. \& Sigman, M. (2008). Modeling longitudinal change in the language abilities of children with autism: Parent behaviors and child characteristics as predictors of change. Developmental Psychology, 44(6), 1691-1704.

Siller, M. \& Sigman, M. (2002). The behaviors of parents of children with autism predict the subsequent development of their children's communication. Journal of Autism and Developmental Disorders, 32(2), 77-89.

Singh, N.N., Lancioni, G.E., Winton, A.S.W., Fisher, B.C., Wahler, R.G., Mcaleavey, K., et al. (2006). Mindful parenting decreases aggression, noncompliance, and selfinjury in children with autism. Journal of Emotional and Behavioral Disorders, 14, 169-177.

Sofronoff, K., Leslie, A., \& Brown, W. (2004). Parent management training and Asperger syndrome. Autism, 8(3), 301-317. 
Solomon, R., Necheles, J., Ferch, C., \& Bruckman, D. (2007). Pilot study of a parent training program for young children with autism. Autism, 11(3), 205-224.

Spiker, D., Boyce, G.C., \& Boyce, L.K. (2002). Parent-child interactions when young children have disabilities. International Review of Research in Mental Retardation, 25, 35-70.

Sroufe, L.A. (1996). Emotional development: The organization of emotional life in the early years. New York: Cambridge University Press.

Stern, D.N. (2002). The first relationship: Infant and mother. Cambridge, MA: Harvard University Press.

Stevens, J. P. (2009). Applied multivariate statistics for the social sciences (5th ed.).

Mahwah, NJ: Lawrence Erlbaum Associates.

Stuart, M. \& McGrew, J.H. (2009). Caregiver burden after receiving a diagnosis of an autism spectrum disorder. Research in Autism Spectrum Disorders, 3, 86-97.

Swedo, S. (2009). Report of the DSM-V neurodevelopmental disorders work group. Retrieved June 12, 2009, From American Psychiatric Association Web site: http://www.psych.org/MainMenu/Research/DSMIV/DSMV/DSMRevisionActivit ies/DSM-V-Work-Group-Reports/Neurodevelopmental-Disorders-Work-GroupReport.aspx.

Symon, J.B. (2005). Expanding interventions for children with autism: Parents as trainers. Journal of Positive behavioral Interventions, 7, 159-173.

Tomasello, M., Carpenter, M., Behne, T., \& Moll, H. (2005). Understanding and sharing intentions: The ontogeny and phylogeny of cultural cognition. Behavioral and 
Brain Sciences, 28(5), 675-691.

Tomasello, M. (2007). Cooperation and communication in the $2^{\text {nd }}$ year of life. Society for Research in Child Development, 1(1), 8-12.

Travis, L.L. \& Sigman, M. (1998). Social deficits and interpersonal relationships in autism. Mental Retardation and Developmental Disabilities, 4, 65-72.

Trevarthen, C. \& Hubley. P. (1978). Secondary intersubjectivity: Confidence, confiding and acts of meaning in the first year. In A. Lock (Ed.), Action, gesture and symbol (pp. 183-229). London: Academic Press.

Trevarten, C. \& Aitken, K.J. (2001). Infant intersubjectivity: Research, theory, and clinical applications. Journal of Child Psychology and Psychiatry, 42(1), 3-48.

Trevarthen, C., Aitken, K.J., Papoudi, D., \& Robarts, J. (1998). Children with autism: Diagnosis and interventions to meet their needs. London: Jessica Kingsley Publishers.

Ungerer, J.A., \& Sigman, M. (1981). Symbolic play and language comprehension in autistic children. Journal of the American Academy of Child Psychiatry, 20,318337.

Valiente, C., Fabes, R.A., Eisenberg, N., \& Spinrad, T.L. (2004). The relations of parental expressivity and support to children's coping with daily stress. Journal of Family Psychology, 18(1), 97-106.

Van Hooste, A. \& Maes, B. (2003). Family factors in the early development of children with Down syndrome. Journal of Early Intervention, 25, 296-309.

Ventola, P.E., Kleinman, J., Pandey, J., Barton, M., Allen, S., Green, J., et al. (2006). Agreement among four diagnostic instruments for autism spectrum disorders in 
toddlers. Journal of Autism and Developmental Disorders, 36, 839-847.

Warfield, M.E. (2005). Family and work predictors of parenting role stress among twoearner families of children with disabilities. Infant \& Child Development, 14, 155176.

Whittingham, K., Sofronoff, K., Sheffield, J., \& Sanders, M.R. (2009). Stepping Stones Triple P: An RCT of a parenting program with parents of a child diagnosed with an autism spectrum disorder. Journal of Abnormal Child Psychology, 37, 469480.

Wieder, S. \& Greenspan, S.I. (2003). Climbing the symbolic ladder in the DIR model through floor time/interactive play. Autism, 7(4), 425-435.

Willemsen-Swinkely, S.H.N., Bakermans-Kranenburg, M.J., Buitelaar, J.K., van Ijzendoorn, M.H., and van Engeland, H. (2000). Insecure and disorganized attachment in children with a pervasive developmental disorder: relationship with social interaction and heart rate. Journal of Child Psychology and Psychiatry, 41, $759-768$.

Williams, J.H.G., Whiten, A., \& Singh, T. (2004). A systematic review of action imitation in autistic spectrum disorder. Journal of Autism and Developmental Disorders, 34(3), 285-299.

Winerman, L. (2004). Effective education for autism. Monitor on Psychology, 35(11), 46.

Wing, L., Gould, I., Yeates, S.R., \& Brierly, L.M. (1977). Synbolic play in severely mentally retarded and in autistic children. Journal of Child Psychology and Psychiatry, 18, 167-178.

Woodgate, R.L., Ateah, C., \& Secco, L. (2008). Living in a world of our own: The 
experience of parents who have a child with autism. Qualitative Health Research, 18(8), 1075-1083.

Yarrow, L.J. (1963). Research in dimensions of early maternal care. Merrill-Palmer Quarterly, 9, 101-114.

Yirmiya, N. \& Sigman, M. (2001). Attachment in children with autism. In J. Richer \& S. Coates (Eds.), Autism-the search for coherence (pp. 53-63). London: Jessica Kingsley Publishers.

Young, J.M. \& Hauser-Cram, P. (2006). Mother-child interaction as a predictor of mastery motivation in children with disabilities born preterm. Journal of Early Intervention, 28, 252-263. 
Appendix A: Parent Research Consent Form

\section{Autism Severity and Parent-Child Interaction Parent Consent Form}

You are invited to participate in a research study of your child's level of autism severity and aspects of the relationship and interaction you have with your child. You were selected as a potential participant in this study because you are a parent of a child between the ages of 4 and 15 with a diagnosis of autism. I ask that you read this form carefully and let us know if you have any questions prior to agreeing to participate in the study. This study is being conducted by Nicole Beurkens, a doctoral candidate at Walden University. While Nicole is an autism specialist who provides therapy to children with autism and their parents at the Horizons Developmental Remediation Center, her role in this research project is as a researcher and not a therapist. Therefore, she will not be providing any consultation or therapy services to participants during the course of this study.

Background Information: The aim of this study is to improve understanding of how severity of autism symptoms in children impact the relationships and interactions they have with their parents.

Procedures: Participation in this study involves the following:

- 10-20 minutes of play activities with your child at the Horizons Developmental Remediation Center which will be videotaped for later analysis

- 45-60 minutes of your child participating in the Autism Diagnostic Observation Schedule (ADOS) in the clinic setting

- 10-15 minutes to complete a questionnaire regarding your relationship with your child 
If you would like to participate in this study, please sign this informed consent form and return it via mail to: Nicole Beurkens, $312068^{\text {th }}$ Street, Caledonia, MI 49316. Once your signed consent form has been received you will receive a phone call to schedule your testing and activity session.

Compensation: There will be no compensation provided for your participation in this study.

Confidentiality: The records of this study will be held in strict confidence. Any reporting of the results of this study will not include names of participants. All materials will be numerically coded so as to avoid identification with specific participants. Research records will be kept in a locked file cabinet and stored on a password-protected hard drive. Only the researcher and research assistant will have access to these records.

Voluntary Nature of the Study: Your participation in the study is voluntary and you are free to withdraw at any time during the process.

Risks and Benefits of the Study: There are minimal risks involved in this study. There is no treatment being applied that could induce harm or benefit to your child. There are benefits to the field of autism in general, as information gained in this study will improve understanding of how autism impacts parent-child interaction and relationships. Even though you and your child will be participating in the study activities at the Horizons Developmental Remediation Center, there is no treatment being provided. It is possible that your child will become mildly upset during the 
testing activities, or that you may experience mild emotional distress when completing survey instruments. Participants are not required to complete any parts of the study that create undue discomfort or stress for parents or child.

Contacts and Questions: The researcher conducting this study is Nicole Beurkens. She can be reached by email at nicole.beurkens@waldenu.edu. The researcher’s advisor is Dr. Magy Martin, who can be reached by email at magy.martin@waldenu.edu. If you would like to speak with a Walden University representative about your rights concerning this study you may contact Dr. Leilani Endicott at 800-925-3368, ext. 1210.

A copy of this form for your records will be provided upon your request. If you would like to receive a copy of the results of this study following its completion, please indicate by checking here

Statement of Consent: I have read the above information, and have received answers to any questions I asked in regards to the study. I consent to participate in the study and I provide consent to allow my child to participate in the study. My child was provided with study information and details of informed consent in my presence, and has agreed to participate via written or verbal assent.

Printed Name of Parent:

Parent Signature: Date:

Printed Name of Child:

Researcher's Signature: 
Appendix B: Youth assent form

\section{Autism Severity and Parent-Child Interaction Youth Assent Form}

You are invited to participate in a research study about autism and the relationships between children and their parents. You were selected to do the activities for this study because you are between the ages of 4 and 15 and have been diagnosed with autism. Please read this form carefully and let us know if you have any questions before you agree to participate in the study.

Background Information: This study will help us understand how children with autism and their parents spend time together and get along with each other.

Procedures: To participate in this study you will spend time doing the following things:

- 10-20 minutes playing with your parent or guardian at the Horizons Developmental Remediation Center (we will videotape you so we remember what you did together)

- 45-60 minutes doing activities, such as playing with toys and answering questions, with the researcher in the clinic (we will videotape you so we remember the activities)

Confidentiality: All of your information will be kept private. Your name and video footage will not be seen by anyone except the researcher and the person helping her.

Voluntary Nature of the Study: You do not have to participate in this study if you do not want to. If you decide to participate but change your mind, you can stop participating at any time.

Risks and Benefits of the Study: Participating in this study is very safe. There is nothing good or bad that will happen to you by participating. It is possible that you may not like all of the 
activities and may not want to do them. You do not have to finish any activities that are very upsetting or uncomfortable for you.

Contacts and Questions: The researcher conducting this study is Nicole Beurkens. She can be reached by email at nicole.beurkens@,waldenu.edu. The researcher's advisor is Dr. Magy Martin, and she can be reached by email at magy.martin@waldenu.edu. If you would like to talk to a Walden University representative about your rights concerning this study you may contact Dr. Leilani Endicott at 800-925-3368, ext. 1210.

This research study has been explained to you and you understand what will happen and why. You have discussed this study with your parent(s)/legal guardian and have decided you would like to participate. You understand that a copy of this form will be given to your parent(s)/legal guardian to keep, and that they will be asked for permission to allow you to participate in this study. If you do not understand this study or do not want to participate in it, please do not sign this form.

Child's Printed Name:

Child's Signature: Date:

Parent or Guardian Name:

Printed Name of Researcher Obtaining Assent:

Researcher's Signature: Date: 
Appendix C: Child Verbal Assent Form

\section{Autism Severity and Parent-Child Interaction Verbal Assent Script}

My name is Nicole Beurkens and I am a student at Walden University. I am doing some activities with children and their parents to learn how they play and get along together. I have chosen kids your age to participate, and would like to explain what you would need to do so you can decide if you want to participate or not.

If you decide to do these activities you will need to spend 10-20 minutes playing with your mom or dad at my office. I will videotape you and your parent playing so I can remember what you did together. You will also need to spend about an hour doing activities with me, such as playing with toys and answering questions. These activities will also be videotaped.

All of your information will be kept private. I will not tell anyone, except the person helping me with the activities, that you participated or give them any personal information about you. You do not have to participate in these activities if you don't want to. If you decide to try the activities but change your mind, you can stop at any time.

Participating in this study is very safe and there is nothing good or bad that will happen to you by participating. 
If you have any questions please ask me now or anytime during the activities. Your parents have agreed to participate and you discuss it with them. Now that I have explained what you will be doing and why, I need to know if you would like to participate. 


\section{Appendix D: Videotaped Activity Protocol}

Participants: Parent and Child

Location: Clinic Setting

Materials: Variety of balls, beanbags, board/card games, blocks, puzzles, and other items appropriate for the child's age and functioning level

Time Frame: 10-20 minutes

Instructions: "Please spend some time playing together in this room with the materials available. You may use the materials in whatever ways you wish together. Set whatever limits and boundaries you would with your child at home." 


\section{Appendix E: Demographic Questionnaire}

Completion of this questionnaire is important for understanding the specific population studied and how these factors may influence the results of the study. All information provided will remain confidential, and any published use of this data will not include identifying information of study participants.

\section{Child Information}

Gender (Check one): ___ Male __ Female Age:

Current Grade:

Diagnosis/Diagnoses:

Age Diagnosed with Autism:

Medical Conditions / Health Problems:

Ethnicity (Check all appropriate) African American Asian, Asian American Caucasian/White Hispanic/Latino Native American ___ Other

\section{Parent Information}

We are a (check one): Two-parent family Single-parent family Who is the primary parent (the parent who spends the most time with the child) (check one): Mother Father 
Approximate number of hours child spends with primary parent per day:

Primary Parent Age:

Primary Parent Educational Level (Check one):

$\begin{array}{ccc}8^{\text {th }} \text { Grade Education } & \text { Some High School } & \text { H High School Diploma } \\ \text { Some College } & \quad \text { College Degree } & \end{array}$

Primary Parent Ethnicity

(Check all appropriate): African American Asian, Asian American Caucasian/White Hispanic/Latino Native American Other

Family Information

Number of family members currently living in the home:

Ages of any other children in the home:

Diagnosis/Diagnoses of any other children in the home: 
Appendix F: ADOS Revised Scoring Algorithms

Child ID:

Date of Birth:

Gender:

Date of Evaluation:

Examiner:

Chronological Age:

ADOS Module 1, No Words
(Code of 3 or 8 on 'Overall Level of Language'; Item A1)

\begin{tabular}{|c|c|}
\hline $\begin{array}{l}\text { ADOS Algorithm for DSM-IV/ICD-10 Autis } \\
\text { (Convert scotes of } 3 \text { on the protocol to } 2 \text {, and treat all scores }\end{array}$ & $\begin{array}{l}\text { sis } \\
-3 \text { as } 0 .)\end{array}$ \\
\hline Communication & \\
\hline Frequency of Vocalization Directed to Others & $(\mathrm{A}-2)$ \\
\hline Gestures & $(\mathrm{A}-8)$ \\
\hline Reciprocal Social Interaction & \\
\hline Unusual Eye Contact & (B-1) \\
\hline Facial Expressions Directed to Others & $(\mathrm{B}-3)$ \\
\hline Integration of Gaze and Other Behaviors During Social Overtures & $(\mathrm{B}-4)$ \\
\hline Shared Enjoyment in Interaction & $(\mathrm{B}-5)$ \\
\hline Showing & (B-9) \\
\hline Spontaneous Initiation of Joint Attention & (B-10) \\
\hline Response to Joint Attention & (B-11) \\
\hline Quality of Social Overtures & (B-12) \\
\hline Soci & Total \\
\hline Restricted and Repetitive Behaviors & \\
\hline Intonation of Vocalizations or Verbalizations & $(A-3)$ \\
\hline Unusual Sensory Interest in Play Material/Person & (D-1) \\
\hline Hand and Finger and Other Complex Mannerisms & (D-2) \\
\hline Unusually Repetitive Interests or Stereotyped Behaviors & (D-4) \\
\hline Restricted and Repetitive & Total \\
\hline
\end{tabular}

and Restricted and Repetitive Behavior Total

(Autism cut-off $=16 ;$ autism spectrim cut-off $=11$ )

\section{Diagnosis}

ADOS Classification:

Overall Diagnosis: 
Child ID:

Date of Birth:

Gender:

Date of Evaluation:

Examiner:

ADOS Module 1, Some Words

(Code of 0,1 or 2 on 'Overall Level of Language'; Item A1)

\begin{tabular}{|c|c|}
\hline \multicolumn{2}{|c|}{$\begin{array}{l}\text { ADOS Algorithm for DSM-IV/ICD-10 Autism Diagnosis } \\
\text { (Convert scores of } 3 \text { on the protocol to } 2 \text {, and treat all scores other than } 0-3 \text { as } 0 \text {.) }\end{array}$} \\
\hline \multicolumn{2}{|l|}{ Communication } \\
\hline Frequency of Vocalization Directed to Others & $(A-2)$ \\
\hline Pointing & $(\mathrm{A}-7)$ \\
\hline Gestures & $(\mathrm{A}-8)$ \\
\hline \multicolumn{2}{|l|}{ Reciprocal Social Interaction } \\
\hline Unusual Eye Contact & $(\mathrm{B}-1)$ \\
\hline Facial Expressions Directed to Others & (B-3) \\
\hline Integration of Gaze and Other Behaviors During Social Overtures & $(\mathrm{B}-4)$ \\
\hline Shared Enjoyment in Interaction & (B-5) \\
\hline Showing & $(\mathrm{B}-9)$ \\
\hline Spontaneous Initiation of Joint Attention & $(\mathrm{B}-10)$ \\
\hline \multirow[t]{2}{*}{ Quality of Social Overtures } & $(\mathrm{B}-12)$ \\
\hline & Total \\
\hline
\end{tabular}

\section{Restricted and Repetitive Behaviors}

Stereotyped/Idiosyncratic Use of Words or Phrases (A-5)

Unusual Sensory Interest in Play Material/Person (D-1)

Hand and Finger and Other Complex Mannerisms

(D-2)

Unusually Repetitive Interests or Stereotyped Behaviors

(D-4)

Restricted and Repetitive Behavior Total

Social Affect and Restricted and Repetitive Behavior Total

\section{Diagnosis}

ADOS Classification:

Overall Diagnosis: 
Child ID:

Gender:

Examiner:

\section{ADOS Module 2, Younger than Age 5}

\begin{tabular}{|c|c|}
\hline \multicolumn{2}{|c|}{$\begin{array}{l}\text { ADOS Algorithm for DSM-IV/ICD-10 Autism Diagnosis } \\
\text { (Convert scores of } 3 \text { on the protocol to } 2 \text {, and treat all scores other than } 0-3 \text { as } 0 . \text {.) }\end{array}$} \\
\hline \multicolumn{2}{|l|}{ Language and Communication } \\
\hline Pointing & $(\mathrm{A}-7)$ \\
\hline Descriptive, Conventional, Instrumental, or Informational Gestures & $(\mathrm{A}-8)$ \\
\hline \multicolumn{2}{|l|}{ Reciprocal Social Interaction } \\
\hline Unusual Eye Contact & $(\mathrm{B}-1)$ \\
\hline Facial Expressions Directed to Others & $(\mathrm{B}-2)$ \\
\hline Shared Enjoyment in Interaction & $(\mathrm{B}-3)$ \\
\hline Showing & (B-5) \\
\hline Spontaneous Initiation of Joint Attention & (B-6) \\
\hline Quality of Social Overtures & $(\mathrm{B}-8)$ \\
\hline Amount of Reciprocal Social Communication & (B-10) \\
\hline \multirow[t]{2}{*}{ Overall Quality of Rapport } & $(\mathrm{B}-11)$ \\
\hline & Total \\
\hline \multicolumn{2}{|l|}{ Restricted and Repetitive Behaviors } \\
\hline Stereotyped/Idiosyncratic Use of Words or Phrases & $(A-5)$ \\
\hline Unusual Sensory Interest in Play Material/Person & (D-1) \\
\hline Hand and Finger and Other Complex Mannerisms & $(\mathrm{D}-2)$ \\
\hline Unusually Repetitive Interests or Stereotyped Behaviors & (D-4) \\
\hline \multicolumn{2}{|c|}{ Restricted and Repetitive Behavior Total } \\
\hline
\end{tabular}

\section{Social Affect and Restricted and Repetitive Behavior Total}

Date of Birth:

Date of Evaluation:

Chronological Age:

(A-7)

(B-1)

(B-2)

(B-6)

$(\mathrm{B}-10)$

$(\mathrm{A}-5)$

(D-2)

(D-4)

(Autism cut-off $=10 ;$ autism spectrum cut-off $=7$ )

Diagnosis

ADOS Classification:

Overall Diagnosis: 
Child ID:

Gender:

Examiner:
Date of Birth:

Date of Evaluation:

\section{ADOS Module 2, Aged 5 Years or Older}

\section{ADOS Algorithm for DSM-IV/ICD-10 Autism Diagnosi}

(Convert scores of 3 on the protoool to 2 , and treat all scores other than $0-3$ as 0 .)

Language and Communication

Pointing

(A-7)

Descriptive, Conventional, Instrumental, or Informational Gestures

(A-8)

\section{Reciprocal Social Interaction}

Unusual Eye Contact

(B-1)

Facial Expressions Directed to Others

Shared Enjoyment in Interaction

Showing

Spontaneous Initiation of Joint Attention

Quality of Social Overtures

Amount of Reciprocal Social Communication

(B-2)

(B-3)

(B-5)

(B-6)

(B-8)

(B-10)

Overall Quality of Rapport

(B-11)

Social Affect Total

\section{Restricted and Repetitive Behaviors}

Stereotyped/Idiosyncratic Use of Words or Phrases (A-5)

Unusual Sensory Interest in Play Material/Person

(D-1)

Hand and Finger and Other Complex Mannerisms

(D-2)

Unusually Repetitive Interests or Stereotyped Behaviors

(D-4)

Restricted and Repetitive Behavior Total

Social Affect and Restricted and Repetitive Behavior Total

(Autism cut-off $=9$; autism spectrum cut-off $=8$ )

\section{Diagnosis}

ADOS Classification:

Overall Diagnosis: 
Child ID:

Gender:
Examiner:

Date of Birth:

Date of Evaluation:

Chronological Age:

ADOS Module 3

\begin{tabular}{l} 
ADOS Algorithm for DSM-IV/ICD-10 Autism Diagnosis \\
(Convert scores of 3 on the protocol to 2, and treat all scores other than 0-3 as 0.) \\
Language and Communication \\
Reporting of Events \\
Conversation \\
Descriptive, Conventional, Instrumental, or Informational Gestures \\
Reciprocal Social Interaction \\
Unusual Eye Contact \\
Facial Expressions Directed to Others \\
Shared Enjoyment in Interaction \\
\begin{tabular}{ll} 
Quality of Social Overtures & (A-9) \\
Quality of Social Response & (B-2) \\
Amount of Reciprocal Social Communication & (B-4) \\
Overall Quality of Rapport & (B-7) \\
& (B-8) \\
& (B-9) \\
& (B-10) \\
\hline Restricted and Repetitive Behaviors & Social Affect Total \\
Stereotyped/Idiosyncratic Use of Words or Phrases & (A-4) \\
Unusual Sensory Interest in Play Material/Person & (D-1) \\
Hand and Finger and Other Complex Mannerisms & (D-2) \\
Excessive Interest in or References to Highly Specific Topics & (D-4) \\
\multicolumn{1}{|c|}{ Restricted and Repetitive Behavior Total } \\
\hline
\end{tabular} \\
\hline
\end{tabular}

Social Affect and Restricted and Repetitive Behavior Total

\section{Diagnosis}

ADOS Classification:

Overall Diagnosis: 
Appendix G: Permission to Use Revised ADOS Algorithms

Hi, Nicole.

I am a graduate student of Cathy Lord's, and she asked me to respond to your email below. Here are a few papers on the revised algorithms and extensions for their use. We've also attached the algorithm protocols as we use them at our center. The ADOS publisher, WPS, is currently in the process of publishing the revised algorithms, so please don't share these preliminary protocols with other labs. Thanks for your interest,

Kaite

Katherine Gotham, M.A.

Clinical Psychology Doctoral Student

University of Michigan Autism and Communication Disorders Center (UMACC)

1111 E. Catherine Street

Ann Arbor, Michigan 48109

Phone: 734-615-7889

Fax: 734-936-0068

The information included in this transmission may be confidential and/or legally privileged and is intended only for the use of the designated addressee. If you are not the intended recipient, or authorized to receive e-mail for the addressee, you may not use, act upon, copy or disclose to anyone the message or any information contained in the message. If you have received this transmission in error, please notify the sender immediately, and delete/destroy the message. Thank you.

From: Nicole Beurkens [nicole@horizonsdrc.com]

Sent: Monday, July 06, 2009 9:07 PM

To: Lord, Catherine

Subject: ADOS revised algorithms and dissertation research

Dr. Lord, I am a Clinical Psychology $\mathrm{PhD}$ student working on my dissertation regarding the relationship between severity of autism symptoms and aspects of parent-child interaction. I live in Michigan (Grand Rapids area) and am working with Dr. Jessica Hobson in the UK on data collection and on-going research on related topics. She recommended that I contact you regarding information you presented at the recent IMFAR conference on revised ADOS algorithms. For my study I am using the ADOS in order to confirm that participants are indeed on the spectrum. Jessica indicated that your new 
algorithms improve the compatibility of scores across modules and also represent symptom severity more explicitly. I would greatly appreciate the opportunity to use these most current algorithms in my dissertation research. Please let me know if this is a possibility and, if so, how I should proceed with accessing them. Also, if you have any studies or presentations regarding these changes I would appreciate having them to reference in my literature review.

Thank you for your time.

Sincerely,

Nicole Beurkens

Nicole Beurkens, Director

Horizons Developmental Remediation Center

3120 68th Street SE

Caledonia, MI 49316

(616) 698-0306

www.horizonsdrc.com

NOTICE TO RECIPIENT: This e-mail is meant for only the intended recipient of the transmission, and may be a communication privileged by law. If you received this e-mail in error, any review, use, dissemination, distribution, or copying of this e-mail is strictly prohibited. Please notify me immediately of the error by return e-mail and delete this message from your system. Thank you in advance for your cooperation. 


\section{Appendix H: DCS Coding Instructions}

The ratings of each subscale are based on observed behaviours and on general impressions. Rating in this way enables raters to observe more sensitively than just counting what they observe, and to consider the interactive aspect of the subscale elements within a dyadic context.

All raters must be thoroughly familiar with the definitions of each subscale and with the system of rating described below. It is expected that raters are knowledgeable regarding child development patterns and that inter-rater reliability has been achieved.

In order to maintain inter-rater reliability and neutrality, all coders are trained to complete the rating scales in the following manner:

1. The rater begins by watching the full ten-minute video clip in its entirety without regard to the rating scale.

2. The rater watches the video a second time, attending to the first 8 subscales individually, stopping the tape if necessary to more closely observe any specific aspect. The rater may write brief notes in the space provided to serve as clarification for the rating. The 8 specific subscales are coded considering one aspect at a time, in order, after this second viewing.

3. After completing ratings for the 8 specific subscales, the 9th Overall Rating is scored.

4. All subscales are rated from 1 to 7 , with 1 representing developmentally problematic interactive behaviour to 7 representing particularly effective dyadic functioning. Scores indicating more effective interactive patterns are not to be expected on all subscales, nor do scores of 1 or 2 on one 
or more subscales indicate pathology. A final Overall Rating provides the rater with the possibility to code an overall impression which may be at odds with several of the previously rated subscales, and is especially useful when idiosyncratic or highly individual behaviours characterize the dyad. The definitions of ratings numbered 1,3 , and 7 are well described. It is not necessary for the dyad to demonstrate all the aspects listed under a rating to receive the score for that rating. Rather, the definitions listed in each rating serve to define major characteristics of the interaction for the subscale. If the rater observes that the dyad (both or either member) demonstrates shared characteristics from two categories, the dyad receives a rating between the two categories. For example, a dyad which is characterized by aspects of both category 3 and category 5 , would receive a rating of 4 on that subscale.

5. If the rater cannot assign a rating to a subscale, the subscale is scored 9 , and the rater notes the reason for this assignment (e.g. back was turned during the whole tape, child appeared sick etc.) or any bizarre, antisocial or immoderate patterns. 
Subject

Rater

Date

$\begin{array}{lllllllll}\text { 1) Co-ordination } & 1 & 2 & 3 & 4 & 5 & 6 & 7 & 9\end{array}$

2) Communication $\quad \begin{array}{llllllll}1 & 2 & 3 & 4 & 5 & 6 & 7 & 9\end{array}$

3) Partner Roles $\quad \begin{array}{llllllll}1 & 2 & 3 & 4 & 5 & 6 & 7 & 9\end{array}$

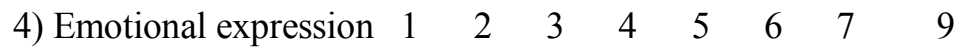

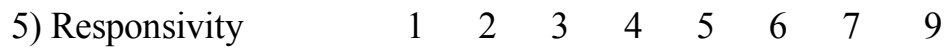

6) Tension/Relaxation $\quad \begin{array}{lllllllll}1 & 2 & 3 & 4 & 5 & 6 & 7 & 9\end{array}$

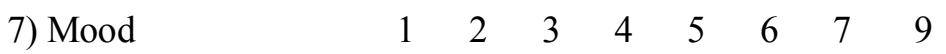

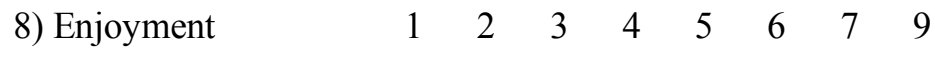

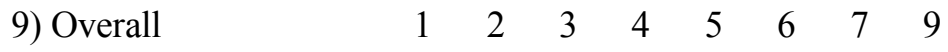


Table 1 Summary description of the coding schema for the quality of mother child interactions

\begin{tabular}{|c|c|c|c|c|c|c|c|}
\hline & Poor equality & Moderate quality & High quality & \multirow[b]{2}{*}{$\begin{array}{l}\text { Responsivity/ } \\
\text { Sensitivity }\end{array}$} & Poor quality & Moderate quality & High quasily \\
\hline \multirow[t]{2}{*}{ Coordination } & \multirow[t]{2}{*}{$\begin{array}{l}\text { " liutle fexiblity } \\
\text { " laxks smoothness } \\
\text { " sepurze and } \\
\text { unrelated } \\
\text { setivities } \\
\text { "inlense friction }\end{array}$} & \multirow[t]{2}{*}{ 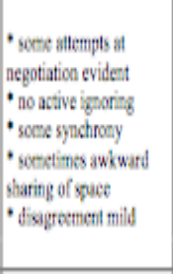 } & \multirow[t]{2}{*}{ 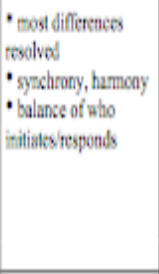 } & & 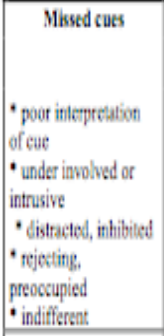 & 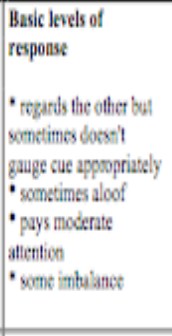 & $\begin{array}{l}\text { Balanced response } \\
\text { Pattern } \\
\text { "evidence of ability } \\
\text { to se other's } \\
\text { Perspective } \\
\text { "good attention wo other } \\
\text { "axcepting, empathy } \\
\text { "balance }\end{array}$ \\
\hline & & & & \multirow{4}{*}{$\begin{array}{l}\text { Tension/ } \\
\text { Relaxation }\end{array}$} & Tense, anxious & Moderate anxicty & Open, relaxed \\
\hline \multirow[t]{2}{*}{ Communication } & \multirow{2}{*}{ 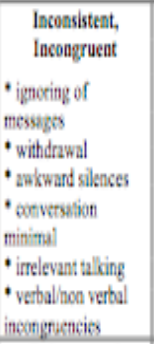 } & \multirow[t]{2}{*}{ 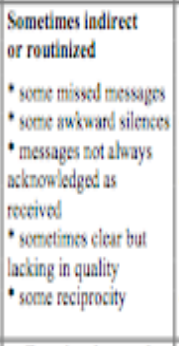 } & \multirow[t]{2}{*}{ 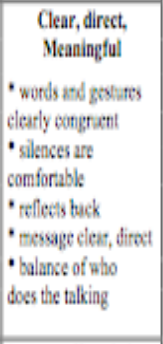 } & & $\begin{array}{l}\text { " nervous mannerims } \\
\text { co foot staking } \\
\text { "clevalod activity } \\
\text { level } \\
\text { cq. unable to sit still } \\
\text { "nus-on spech }\end{array}$ & $\begin{array}{l}\text { - nervous marnerisms } \\
\text { bat not prevailing } \\
\text { 'st ease gencrilly but } \\
\text { shous differences } \\
\text { between free and } \\
\text { structured activities }\end{array}$ & $\begin{array}{l}\text { "no anxiety evident on } \\
\text { cither part } \\
\text { 'st ese for whole } \\
\text { taped erent } \\
\text { "questions genuine, } \\
\text { Related }\end{array}$ \\
\hline & & & & & Negative & Mixed quality & Positive \\
\hline \multirow[t]{2}{*}{$\begin{array}{l}\text { Appropriate role } \\
\text { Assumption }\end{array}$} & \multirow[t]{2}{*}{$\begin{array}{l}\text { Role reversal } \\
\text { 'child uses fear and } \\
\text { humilution as control } \\
\text { agent } \\
\text { " oppositional shifts } \\
\text { " gaze aversion } \\
\text { ' rigid pattem or } \\
\text { laisier-aire }\end{array}$} & \multirow[t]{2}{*}{$\begin{array}{l}\text { Functional control } \\
\text { " wdult assumes hishter } \\
\text { tole as a purent some } \\
\text { of the time } \\
\text { "child able a return } \\
\text { to child role } \\
\text { "sone evidene of } \\
\text { control } \\
\text { from child }\end{array}$} & \multirow[t]{2}{*}{ 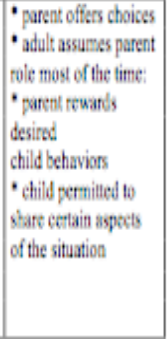 } & & $\begin{array}{l}\text { fozalive } \\
\text { mood ane infrequen|l } \\
\text { and brief } \\
\text { - anger, annoyance } \\
\text { intution, criticism } \\
\text { ' worry, depression }\end{array}$ & $\begin{array}{l}\text { tann } 10 \% \text { and positive } \\
\text { nood less that } 25 \% \\
\text { of the time }\end{array}$ & $\begin{array}{l}\text { mood are rebited to } \\
\text { sonething obvious } \\
\text { and real } \\
\text { "enconagenent } \\
\text { " modulated affest }\end{array}$ \\
\hline & & & & \multirow[t]{2}{*}{ Enjoyment } & $\begin{array}{l}\text { Litte pleasure } \\
\text { - low approval of child }\end{array}$ & $\begin{array}{c}\text { Moderate } \\
\text { - approval of child at }\end{array}$ & $\begin{array}{l}\text { Acceptance } \\
\text { - high appooval of child }\end{array}$ \\
\hline \multirow[t]{2}{*}{$\begin{array}{l}\text { Emotional } \\
\text { Exprosion }\end{array}$} & \multirow[t]{2}{*}{$\begin{array}{l}\text { Disruptive cmotional } \\
\text { cepression } \\
\text { ' difficuly with both } \\
\text { copressing and } \\
\text { respotitg } \\
\text { "very constricted } \\
\text { - intense, over. } \\
\text { charged }\end{array}$} & \multirow[t]{2}{*}{$\begin{array}{l}\text { Moderate balance of } \\
\text { emotional opression } \\
\text { "positive and negutive } \\
\text { oxpessions } \\
\text { physial postines } \\
\text { implies } \\
\text { souse accessibility } \\
\text { "emotios blended }\end{array}$} & \multirow[t]{2}{*}{ 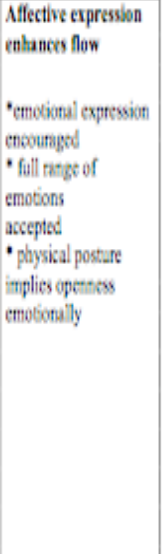 } & & $\begin{array}{l}\text { " frebutls conlact } \\
\text { allempls } \\
\text { - frecuent or long } \\
\text { dunation of disinterest } \\
\text { " cold, boned }\end{array}$ & $\begin{array}{l}\text { scone poinl } \\
\text { "wanthe vident at } \\
\text { some point } \\
\text { "enjoywent evident } \\
\text { more } \\
\text { by ote partes } \\
\text { "detaktid sume of the } \\
\text { time }\end{array}$ & $\begin{array}{l}\text { long of frequel } \\
\text { engigament in } \\
\text { astivity } \\
\text { "sustained wamth } \\
\text { "empathic involvement } \\
\text { "engigement clat }\end{array}$ \\
\hline & & & & Overall & $\begin{array}{l}\text { P0or quality } \\
\text { - basically not } \\
\text { interested } \\
\text { in the other, } \\
\text { indifference } \\
\text { ' iniecessible } \\
\text { ' no plessure } \\
\text { ' much discond and } \\
\text { conflixt }\end{array}$ & $\begin{array}{l}\text { Moderate quality } \\
\text { - bulance of intenaction } \\
\text { - appears accessible, } \\
\text { modentaly responsive } \\
\text { "some enjoytent } \\
\text { "positive almosphere } \\
\text { half of the time }\end{array}$ & $\begin{array}{l}\text { High quality } \\
\text { - authentic interest } \\
\text { " continually responsive } \\
\text { "continuous enjoyment } \\
\text { " barmonious, agterable } \\
\text { "quality of interaction } \\
\text { is high }\end{array}$ \\
\hline
\end{tabular}


Appendix I: Permission to Use DCS

From: <edegan@dsuper.net>

Date: Wed, 23 Dec 2009 16:28:27 -0500 (EST)

To: Nicole Beurkens <nicole@horizonsdrc.com>

Subject: Re: Dyadic Coding Scale

\section{TO WHOM IT MAY CONCERN:}

This is to give my permission for Nicole Beurkens to use the Dyadic Coding Scale, and any developmental changes which she may devise to suit her research subjects, in her doctoral research.

Nancy Humber, Ph.D

Hi Nancy,

$>$ I hope this finds you enjoying the start of winter and the holiday season.

$>$ My dissertation proposal is in the final stages of approval, and my

$>$ committee has requested that I obtain a brief letter from you indicating

$>$ your willingness to allow me to use the DCS for my study. You may reply

$>$ to

$>$ this email with your note of permission to make it simple. I will attach

$>$ whatever you send as an appendix to the proposal showing that you granted

$>$ permission. Thank you so much!

$>$ Nicole

$>$

$>$

> On 11/2/09 12:12 PM, "edegan@dsuper.net" <edegan@dsuper.net> wrote:

$>$

>> Dear Nicole,

$>>$

>> Sorry I have been so long in replying. I have been away. I am retired

$>>$ and

>> no longer at the university, so I had to got through files on an old

$>>$ computer.

$>>$

$>>$ I assume you have read the article in Orthopsychiatry - please fell free

$>>$ to ask me for any clarifications. What I am sending you are the rating

>> scales for the Mother-child interactions, and the chart for determining

>> what the ratings should be. Don't hesitate to contact me if I can be of help.

$>>$

>> Nancy Humber, Ph.D 
Curriculum Vitae

\title{
Nicole Michelle Beurkens
}

7711 Kalamazoo Avenue, Byron Center, MI 49315

(616) 554-1445 - nicole.beurkens@waldenu.edu

\author{
ACADEMIC EXPERIENCE \\ 2010 Candidate for Doctor of Philosophy - Clinical Psychology \\ Walden University - Minneapolis, Minnesota \\ 2002 Master of Education in Special Education \\ Oakland University - Rochester, Michigan \\ 1997 Bachelor of Arts in Special Education, Summa Cum Laude \\ Hope College - Holland, Michigan
}

\section{PROFESSIONAL EXPERIENCE}

6/03 - Present

Founder and Director, Horizons Developmental Remediation Center Provide family-focused treatment services to families of children affected by autism/related disorders. Develop and supervise summer programs, instructional programs, and all therapy programs provided at the center. Manage business-related aspects of the center and provide staff training.

7/00 - 6/07 Autism Consultant - Private Practice

Provided direct and indirect consultative services to students with autism in various public and private school districts. Focused on training development and working with staff and families to increase understanding of autism as well as appropriate interventions. Provided school district evaluations for autism and related disorders.

7/07 - 6/00 Autism Program Teacher - Kentwood Public Schools

Developed and taught in a program serving students with autism ages 312. Implemented a curriculum addressing communication, social, behavioral, and sensory needs. Worked with families to address needs at home and in the community.

\section{LICENSES AND CERTIFICATIONS}

6/01 to present

State of Michigan Certified Teacher - Professional Education Certificate

\#CC-047610090796

Elementary K-5 All Subjects

Elementary K-8 Self Contained Classroom

Learning Disabilities K-8

Autistic K-12

\section{PROFESSIONAL MEMBERSHIPS}

American Psychological Association (APA)

Council for Exceptional Children (CEC) 